\title{
Why Issue Mandatory Convertibles? Theory and Empirical Evidence
}

\author{
Thomas Chemmanur* \\ Debarshi Nandy** \\ and \\ An Yan***
}

First Version: September 2002

Current Version: March 2003

* Associate Professor, Finance Department, Fulton Hall 440, Carroll School of Management, Boston College, Chestnut Hill, MA 02467, Tel: (617) 552-3980, Fax: (617) 552-0431, email: chemmanu@bc.edu.

** Ph.D. Candidate, Finance Department, Fulton Hall 333, Carroll School of Management, Boston College, Chestnut Hill, MA 02467, Tel: (617) 552-2033, Fax: (617) 552-0431, email: nandyd@bc.edu.

*** Assistant Professor, Finance Area, Graduate School of Business Administration, Fordham University, 113 West $60^{\text {th }}$ Street, New York, NY 10023, Tel: (212) 636-7401, Fax: (212) 7655573, email: ayan@,fordham.edu.

For helpful comments or discussions, we thank Enrique Arzac, Wayne Ferson, Cliff Holderness, Edward Kane, Pete Kyle, Alan Marcus, Phil Strahan, and seminar participants at Boston College. We also thank Sandra Caraballo for excellent research assistance. We alone are responsible for any errors or omissions. 


\title{
Why Issue Mandatory Convertibles? Theory and Empirical Evidence
}

\begin{abstract}
Mandatory convertibles, which are equity-linked hybrid securities that automatically convert to common stock on a pre-specified date, have become an increasingly popular means of raising capital in recent years (about $\$ 20$ billion worth issued in 2001 alone). This paper presents the first theoretical and empirical analysis of mandatory convertibles in the literature. We consider a firm facing a financial market characterized by asymmetric information, and significant costs in the event of financial distress. The firm can raise capital either by issuing mandatory convertibles, or by issuing more conventional securities like straight debt, common stock, and ordinary convertibles. We show that, in equilibrium, the firm issues straight debt, ordinary convertibles, or equity if the extent of asymmetric information facing it is large, but the probability of being in financial distress is relatively small; it issues mandatory convertibles if it faces a smaller extent of asymmetric information but a greater probability of financial distress. Our model provides a rationale for the three commonly observed features of mandatory convertibles: mandatory conversion, capped (or limited) capital appreciation, and a higher dividend yield compared to common stock. We also characterize the equilibrium design of mandatory convertibles. Our model also has implications for the abnormal stock returns upon the announcement of mandatory convertibles and for the post-issue operating performance of mandatory convertible issuers. We test the implications of our theory using a sample of firms which have chosen to issue either mandatory convertibles or ordinary convertibles, and we also study the long-term abnormal stock performance of mandatory convertible issuers. The evidence supports the implications of our theory.
\end{abstract}




\section{Why Issue Mandatory Convertibles? Theory and Empirical Evidence}

" The past two decades have witnessed an explosion of financial innovations.... Along with these changes has come an enormous increase in the demand for the services of financial economists. We are called upon not only to value these new instruments and new strategies, but to design them as well. Like engineers who use physics, financial engineers use the techniques of modern finance to build the financial equivalent of bridges and airplanes. Unfortunately, though, when asked to explain why all of this is happening, and why it takes the forms it does, our answers are much more timid. Not uncommonly, we fall back on old canards such as 'spanning." "

— Stephen Ross, Presidential Address to the American Finance Association, 1989.

\section{Introduction}

Mandatory convertibles are equity-linked hybrid securities such as PERCS (Preferred Equity Redemption Cumulative Stock) or DECS (Debt Exchangeable for Common Stock, or Dividend Enhanced Convertible Securities), which automatically ("mandatorily") convert to common stock on a pre-specified date. Starting from small beginnings in 1988, such mandatory convertibles have become extremely popular in recent times: $\$ 5$ billion worth of mandatory convertibles were issued in 1996 (a quarter of the convertible market); in 2001 , about $\$ 20$ billion worth of mandatory convertibles were issued (about 18\% of the convertible market). Mandatory convertibles have been designed with a variety of payoff structures, and carry different names depending on their payoff structure and the investment bank underwriting their issue: examples are Morgan Stanley's PERCS and PEPS, Merrill Lynch's PRIDES, Salomon Brothers' DECS, and Goldman Sach's ACES. They have been issued by a number of companies, large and small, to raise capital: these include Texas Instruments, General Motors, Citicorp, Sears, Kaiser Aluminium, Reynolds Metals, American Express, First Chicago, Boise Cascade, and All State. Two recent issuers were AT\&T and Motorola, which raised $\$ 900$ million and $\$ 1.2$ billion, respectively, in 2001 by selling mandatory convertibles.

Even though there are differences among the above mentioned variations of mandatory convertibles in their payoff structures as well as in some other provisions, certain fundamental features are common to all of them. Three such features are as follows. First, as discussed above, conversion to equity is mandatory 
at the maturity of the convertible (as against conversion to equity at the option of the security holder in the case of ordinary convertibles). Second, the dividend yield on a mandatory convertible is typically higher than that on the underlying common stock. Third, mandatory convertibles have either a capped or limited appreciation potential compared to the underlying common stock.

It is useful to illustrate the above three features using two examples. The first example illustrates an issue of PERCS. In September 1991, K-Mart Corporation issued $\$ 1.012$ billion worth of PERCS at $\$ 44.00$ (K-Mart stock was also selling at this price on the day of issue). The PERCS paid a dividend of 7.75\%, while K-Mart's common stock was paying a dividend of only $4 \%$ at this time. Each unit of PERCS was mandatorily convertible to one share of K-Mart common stock on September 15, 1994, subject to a cap of $\$ 57.20$ : i.e., if the share price of K-Mart exceeded $\$ 57.20$, each unit of PERCS would receive only a fraction of a share worth a total of $\$ 57.20$. Figure 1(a) gives the payoff at maturity (excluding dividends) of the K-Mart PERCS, as a function of its underlying stock price.

The second example illustrates an issue of PEPS (Premium Equity Participating Securities). In June 2000, Valero Energy Corporation issued $\$ 150$ million worth of PEPS at $\$ 25$ per unit (which was the price of 0.85837 shares of its common stock, which was then selling at $\$ 29.125$ per share). The PEPS paid a quarterly dividend $7.75 \%$, while the dividend on the underlying common stock was only $\$ 2.75 \%$. The PEPS were mandatorily convertible to shares of common stock on August 18th, 2003, with the number of shares per PEPS unit given to investors upon conversion depending on the price of the companies' common stock: if the price of the common was $\$ 29.125$ or below (so that 0.85837 shares would be worth $\$ 25$ or below), then each PEPS unit would receive only 0.85837 shares of common stock, giving them a payoff of $\$ 25$. If the common was between $\$ 29.125$ and $\$ 34.95$, then PEPS holders would receive a variable number of shares such that their total value would remain at $\$ 25$ (in other words, $\$ 25$ was the "cap" value of the PEPS). If, however, the common stock price exceeded a "threshold appreciation price" of $\$ 34.95$ on the mandatory conversion date, each PEPS holder would receive 0.71531 shares of common stock. Figure 1(b) gives the payoff at maturity (excluding dividends) of the Valero PEPS, as a function of its underlying stock price.

Notice that, while the K-Mart PERCS value was completely capped at a price of $\$ 20.28$, the Valero PEPS 


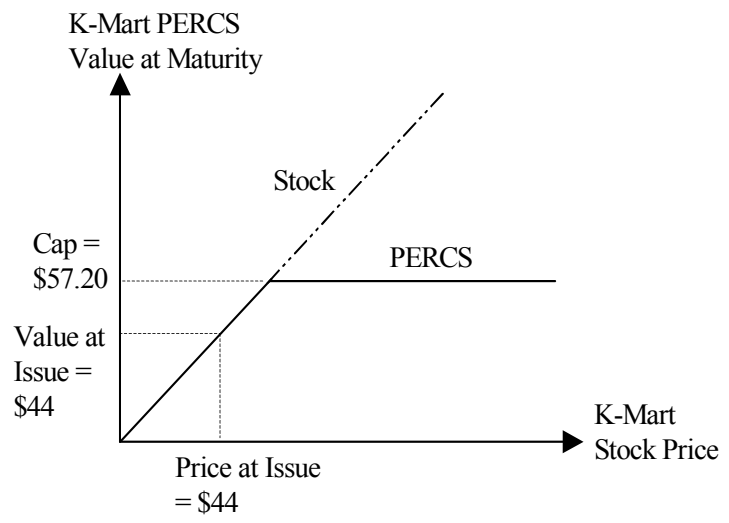

(a) K-Mart PERCS

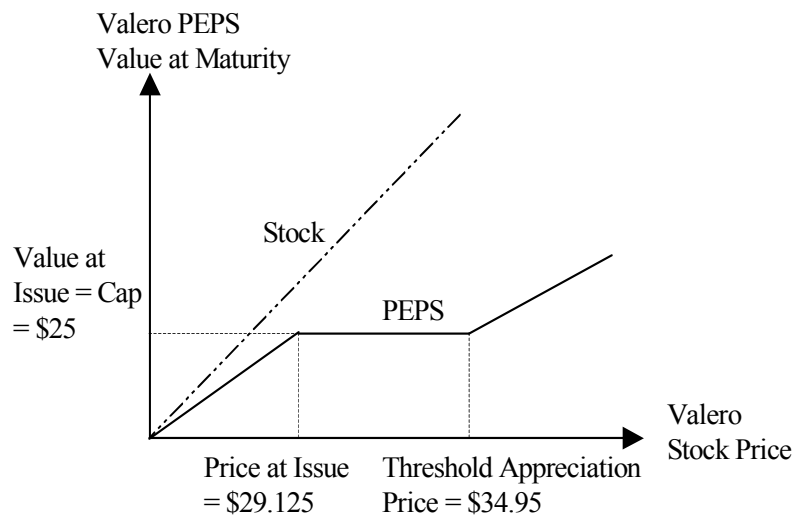

(b) Valero Energy PEPS

Figure 1: Payoff at Maturity (Excluding Dividends) of Two Mandatory Convertibles

holders received a fraction (83.3\%) of the appreciation of the underlying stock beyond the cap value of $\$ 25$.

On the other hand, while holders of PERCS received $100 \%$ of the appreciation of the common stock between the stock price on the date of issue $(\$ 44.00)$ and the cap price of $\$ 57.20$, the Valero PEPS holders did not receive any appreciation on their investment until the stock price exceeded the threshold appreciation price of $\$ 34.95$ (since the cap on PEPS is usually set at the issue price, i.e, $\$ 25$ in the case of Valero PEPS). In other words, the PEPS holder did not share in the first $20 \%$ of the appreciation in the underlying common stock (between the $\$ 25$ cap and the threshold appreciation price of $\$ 34.95$ ). However, notice that both the PERCS and the PEPS issues share the three features, common to all mandatory convertibles, that we discussed above, namely, mandatory conversion, capped (either completely, as in the case of PERCS, or partially, as in the case of PEPS) appreciation potential, and dividend yield significantly in excess of the underlying common stock. ${ }^{1}$

\footnotetext{
1 Both PERCS and PEPS offerings were underwritten by Morgan Stanley. Most other mandatory convertibles, including those underwritten investment banks other than Morgan Stanley, have a payoff structure similar to PERCS and PEPS (though these mandatory convertibles often differ from PERCS and PEPS in terms of many institutional arrangements). Thus, ACES (Automatically Convertible Equity securities), PRIDES (Preferred Redemption Increased Dividend Equity Securities), FELINE PRIDES (Flexible Equity-Linked Exchangeable PRIDES), DECS, SAILS (Stock Appreciation Income Linked Securities), MARCS (Mandatory Adjustable Redeemable Convertible Securities), and TAPS (Threshold Appreciation price Securities) are examples of mandatory convertibles with a payoff structure similar to PEPS. CHIPS (Common-linked Higher Income Participating debt Securities), EYES (Enhanced Yield Equity Securities), TARGETS (Targeted Growth Enhanced Term Securities), and YES (Yield Enhanced Stock) are examples of securities which perform like PERCS. See Morgan Stanley (1998), and Nelken (2000), for a more detailed listing.
} 
The increasing popularity of mandatory convertibles over the last decade as an instrument for raising capital by firms prompt us to raise several questions. When should a firm issue mandatory convertibles to raise capital, rather than issuing ordinary convertibles, or even more conventional securities such as equity or straight debt? What explains the prevalence of the three fundamental features discussed above in almost all mandatory convertibles? How should a mandatory convertible be designed in terms of the mix of various features (e.g., the optimal cap, the number of shares of equity into which the mandatory convertible should be exchanged for in the event of conversion, the dividend yield on the mandatory convertible)? Unfortunately, there has been no theoretical analysis so far in the literature which enables us to answer such questions. Neither has there been a comprehensive empirical study of these securities. The objective of this paper is to develop a theoretical analysis of mandatory convertibles which allows us to answer the above and related questions, and to present empirical evidence regarding the implications of this theory.

Our analysis rests on two assumptions based on certain stylized facts about the mandatory convertibles market (and the securities market in general). First, firms are concerned about the misvaluation of their securities in the capital market, and would like to issue securities which would yield them the required amount of capital with the minimum dilution in the equity holdings of current shareholders. Second, firms are also concerned about the probability of being in financial distress (bankruptcy), and incurring financial distress costs. Thus, we consider a setting of asymmetric information, where firm insiders have more information about the intrinsic value of their firm compared to potential outside investors in the firm. In such a setting, higher valued firms have an incentive to distinguish themselves from lower intrinsic valued firms in order to obtain their true value in the securities market. One way to accomplish this is to issue securities such as straight debt and ordinary (callable) convertibles, which have the possibility of forcing the firm into financial distress: since, for the same amount of debt issued, lower intrinsic valued firms have a higher chance of going into financial distress compared to higher intrinsic valued firms, the former would not wish to mimic such a strategy, enabling higher intrinsic valued firms to separate themselves from lower-intrinsic valued firms, thereby obtaining their true valuation in the securities market.

Such signaling strategies, however, have their own pitfalls. In a world with uncertainty, higher valued 
firms themselves have a positive probability of being in financial distress, and when costs of financial distress are significant, the costs of issuing straight debt or ordinary convertibles to distinguish themselves may exceed the valuation benefits from doing so (recall that there is a significant risk of financial distress in the case of ordinary convertibles, since conversion is at the option of the convertible holder alone). ${ }^{2}$ In such a situation, firms have an incentive to turn to mandatory convertibles. Since conversion to equity is mandatory in the case of these securities, firms do not have to be concerned about incurring financial distress costs if such securities are issued instead of straight debt or ordinary callable convertibles. ${ }^{3}$ At the same time, mandatory convertibles enable the firm to minimize the extent of undervaluation of the firm's securities: we show that, while some extent of undervaluation of intrinsically higher-valued firms is unavoidable if mandatory convertibles are issued, such undervaluation is lower than would be the case if the firm issued other securities (such as equity) which also do not increase the chance of the firm going into financial distress. Thus, whether a firm chooses, in equilibrium, to issue mandatory convertibles, or more conventional securities like straight debt, ordinary callable convertibles, or equity, depends on the magnitude of the costs and benefits of issuing these different securities.

In the above setting, we develop a variety of results relevant to a firm's choice of mandatory convertibles as a means of raising capital. First, we develop predictions regarding the kind of firms which issue mandatory convertibles rather than more conventional securities, and the situations in which such firms will issue mandatory convertibles. In particular, our model predicts that, when faced with a choice between ordinary and mandatory convertibles, firms facing a larger extent of asymmetric information, but a relative smaller probability of financial distress will choose to issue ordinary convertibles, while those facing a smaller extent of asymmetric information, but a larger financial distress probability will issue mandatory convertibles.

\footnotetext{
2 The callability feature of convertibles does not mitigate this danger of the convertibles remaining as a fixed income security and the firm incurring bankruptcy costs. Calling these convertibles in order to force conversion will be optimal for the firm only if the share price is high enough, in which there is no danger of bankruptcy in the first place. In other words, the callability feature of convertibles only serves to expedite conversion by convertible holders in the range of share prices where it is optimal for them to convert to equity in the first place; it cannot force conversion if the stock price is low.

3 This advantage of mandatory convertibles in avoiding the costs associated with financial distress has been noted by practioners. For example, see a recent magazine story entitled "Tech Companies Have a New Currency, and Its Mandatory" (Red Herring, January 2002). We quote: "Because they are guaranteed to convert to equity, potential yield and redemption hassles for their issuers that other bonds carry. 'If the stock drops, you don't get stuck with a bond that you have to continue to service' says F. Barry Nelson, portfolio manager of Advent Capital Management, which has $\$ 900$ million invested in convertibles."
} 
Thus, a larger firm, which is already highly leveraged (or facing a financial downturn) will choose mandatory convertibles over ordinary convertibles, while a smaller firm, which is relatively debt free will make the reverse choice.

Second, we develop a rationale for the prevalence of the three common features of mandatory convertibles discussed above, namely, mandatory conversion, capped (or limited) capital appreciation, and higher dividend yield relative to equity. Third, we characterize the optimal configuration of the above three features as well as the optimal exchange ratio (fraction of a firm's equity the mandatory convertible issue should convert into) for an issue of mandatory convertibles. Fourth, we develop implications for the abnormal returns to the firm's equity upon the announcement of an issue of mandatory convertibles: our analysis predicts that the announcement effect of mandatory convertibles will be either zero or negative, depending upon whether mandatory convertibles are issued in a fully pooling or a partially pooling equilibrium. This prediction implies that, if we split up a sample of mandatory convertible issues by the probability of financial distress of the issuing firm at the time of issue, mandatory convertible issues of firms having a lower financial distress probability can be expected to have a less negative announcement effect. Our analysis also has predictions about the operating performance of a sample of issuers of mandatory convertibles relative to those of a matched sample of non-issuers.

Finally, we test the implications of our theory on a sample of firms which have chosen to issue either ordinary or mandatory convertibles, making use of commonly used proxies for asymmetric information (e.g., number of analysts following a firm, standard deviation of analyst forecasts, forecast error) and probability of financial distress (Altman's Z-score, existing firm leverage). The evidence generally supports the implications of our theory. In particular, we find that it is indeed firms facing a smaller extent of information asymmetry but a larger financial distress probability that issue mandatory convertibles, while those facing a larger extent of information asymmetry and a smaller financial distress probability that issue ordinary convertibles. Our evidence also supports the implications of our theory regarding the announcement effects of mandatory convertible issues and the post-issue operating performance of mandatory convertible issuers relative to that of a matched sample of non-issuers. We also document that mandatory convertible issuers do not 
exhibit long-term negative abnormal stock performance (in contrast to the negative abnormal long-term stock performance of ordinary convertible issuers that has been documented in the literature).

It is not our view here that asymmetric information and financial distress costs are the only two factors driving the issuance of mandatory convertibles. As Miller has noted, a number of financial innovations over the last twenty years have been driving by considerations of minimizing taxes: mandatory convertibles are no exception. Many mandatory convertible securities (e.g., PEPS and FELINE PRIDES) offer tax advantages: e.g., deductibility of the dividend paid, similar to the coupon paid on corporate debt. However, it is worth noting that many of the original mandatory convertible issues were not tax advantaged (i.e., the dividend paid was not tax deductible), so that it is unlikely that the financial innovation of mandatory convertibles issues was prompted purely as a means of minimizing taxes. Rather, it seems to be the case that, while originally driven by other considerations, tax advantaged structures were added to make these securities more attractive to issuers. Another motivation driving the issuance of mandatory convertibles are legal restrictions on liquidating securities faced by large shareholders in some firms. These large shareholders issue mandatory convertibles which are convertible into the equity of their portfolio firms, thus immediately monetizing their holdings in their portfolio firms without having to sell these holdings immediately. Finally, another motivation driving the issuance of some mandatory convertibles may be "clientele" effects, i.e., driven by the desire of issuing firm's to take advantage of institutional investors' desire for higher dividend paying securities. In summary, similar to other securities like debt and equity, the issuance of mandatory convertibles is also probably driven by many different market imperfections: we have chosen to focus here only on asymmetric information and financial distress costs as two of the most important of these, abstracting away from other considerations for the sake of analytical tractability. ${ }^{4}$

The existing literature on mandatory convertibles is quite small. Arzac (1997) provides an good description of some mandatory convertibles such as PERCS and DECS, with some discussion of the valuation of

\footnotetext{
${ }^{4}$ Note that, even if we explicitly include any tax advantages of issuing mandatory convertibles in our theoretical analysis, the equilibria studied here will continue to exist, though the parameter regions in which various equilibria arise will be modified. In other words, our qualitative results will hold even in this case.
} 
these based on the option pricing methodology. ${ }^{5} \quad$ As mentioned before, there have been no theoretical models of the choice of firms between mandatory convertibles and other securities in the literature so far, and almost no empirical literature. Thus, the theoretical literature closest to this paper is the literature on the issue of ordinary convertibles in an environment of asymmetric information: see, e.g., Brennan and Kraus (1987), Constantinides and Grundy (1989), and Stein (1992). ${ }^{6}$ In particular, the rationale for issuing ordinary convertibles in our setting is similar to that in Stein (1992), though ordinary convertibles are not the focus of this paper. It is important to note that, the rationale for the issuance of mandatory convertibles that we present here is completely new, and not derived from explanations for the issuance of any other security (including ordinary convertibles) that has been presented so far in the literature.

The rest of this paper is organized as follows. Section 2 describes the model. Section 3 characterizes the equilibrium of the model and develops results. Section 4 characterizes the equilibrium design of mandatory convertibles. Section 5 describes the implications of the model, and develops testable hypotheses. Section 6 desribes our empirical methodolgy and presents the results of our empirical tests. Section 7 concludes. The proofs of all propositions are confined to the appendix.

\section{The Model}

The model has three dates $(t=0,1,2)$. Consider a risk-neutral entrepreneur owning an all-equity firm. To begin with, we assume that the entrepreneur owns all the equity in the firm: for simplicity, we normalize the number of shares of equity at $\mathrm{t}=0$ to be one. The firm needs to raise an amount of $I$ externally to finance a new positive net present value project. We assume that the firm has no other ongoing projects, so that the cash flows received by the firm are the same as those generated by the new project. We normalize the risk-free rate of return to be zero, and that the investors are risk-neutral.

\footnotetext{
5 There are also a few other practitioner oriented discussions and pedagogical cases on mandatory convertibles. Excellent examples include the HBS cases on Avon Products PERCS (Tiemann, 1989), Telmex PRIDES (Seasholes and Froot, 1996), Times Mirror PEPS (Tufano and Poetzscher, 1996), and Cox Communications FELINE PRIDES (Chacko and Tufano, 2000).

${ }^{6}$ Several other papers provide rationales for issuing ordinary convertibles which are not based on asymmetric information. See e.g. Green (1984), Mayers (1998), Brennan and Kraus (1987), and Brennan and Schwartz (1988).
} 


\subsection{Cash Flow and Information Structure}

There are three types of firms: good (type G hereafter), medium (type M hereafter), or bad (type B hereafter). The cash flows from the new investment are realized at time 2. Each firm receives a gross cash flow of $x_{H}$ (the high cash flow) or $x_{L}$ (the low cash flow) at this date, $x_{H}>I>x_{L}$. The differences between the three types of firms are characterized by their probabilities of receiving the high and low cash flows at time 2. Further, at time 1, these firms "deteriorate" with a certain probability. In the event of deterioration, the firm realizes the low cash flow $x_{L}$ with probability 1 . Thus, the type $\mathrm{G}$ and type $\mathrm{M}$ firms deteriorate with a probability $\phi_{1}$, while the type B deteriorates with a probability $\phi_{2}>\phi_{1}$. In the event there is no deterioration at time 1 , the type $\mathrm{G}$ receives the high cash flow with probability 1 , while both the type $\mathrm{M}$ and type B firms have a probability $1-\delta$ of receiving the high cash flow $x_{H}$ and $\delta$ of receiving the low cash flow $x_{L}$. In summary, the ex ante (time 0) probability of receiving the low cash flow of the type B firm, $\phi_{2}+\left(1-\phi_{2}\right) \delta$, will be greater than that of the type M firm, $\phi_{1}+\left(1-\phi_{1}\right) \delta$, which in turn will be greater than that from the type $\mathrm{G}$ firm, $\phi_{1}$. Thus, the expected cash flow from the type $\mathrm{G}$ firm is greater than that from the type M, which in turn is greater than that from the type B. Since any type of firm's project has positive NPV, $\left[\phi_{2}+\delta\left(1-\phi_{2}\right)\right] x_{L}+(1-\delta)\left(1-\phi_{2}\right) x_{H} \geq I$. The cash flow structure of the three types of firms is depicted in figure 2 .

Firm types are private information to the entrepreneur at time 0 , with outsiders having only a prior probability distribution over firm types. The outsiders' prior of any given firm being of type G, M or B are $\gamma_{1}, \gamma_{2}$, and $\gamma_{3}$ respectively, $\gamma_{1}+\gamma_{2}+\gamma_{3}=1$. At time 1 , however, outsiders observe whether a firm has deteriorated or not. Based on this additional information, they engage in Bayesian updating about the type of the firm. At time 2, all asymmetric information is resolved. The sequence of events is given in figure 3.

\subsection{Menu of Securities}

The entrepreneur can issue one of four different securities to raise the required external financing $I$ : straight risky debt ("straight debt" hereafter), ordinary callable convertible debt ("ordinary convertible" hereafter), mandatory convertibles, or equity. 


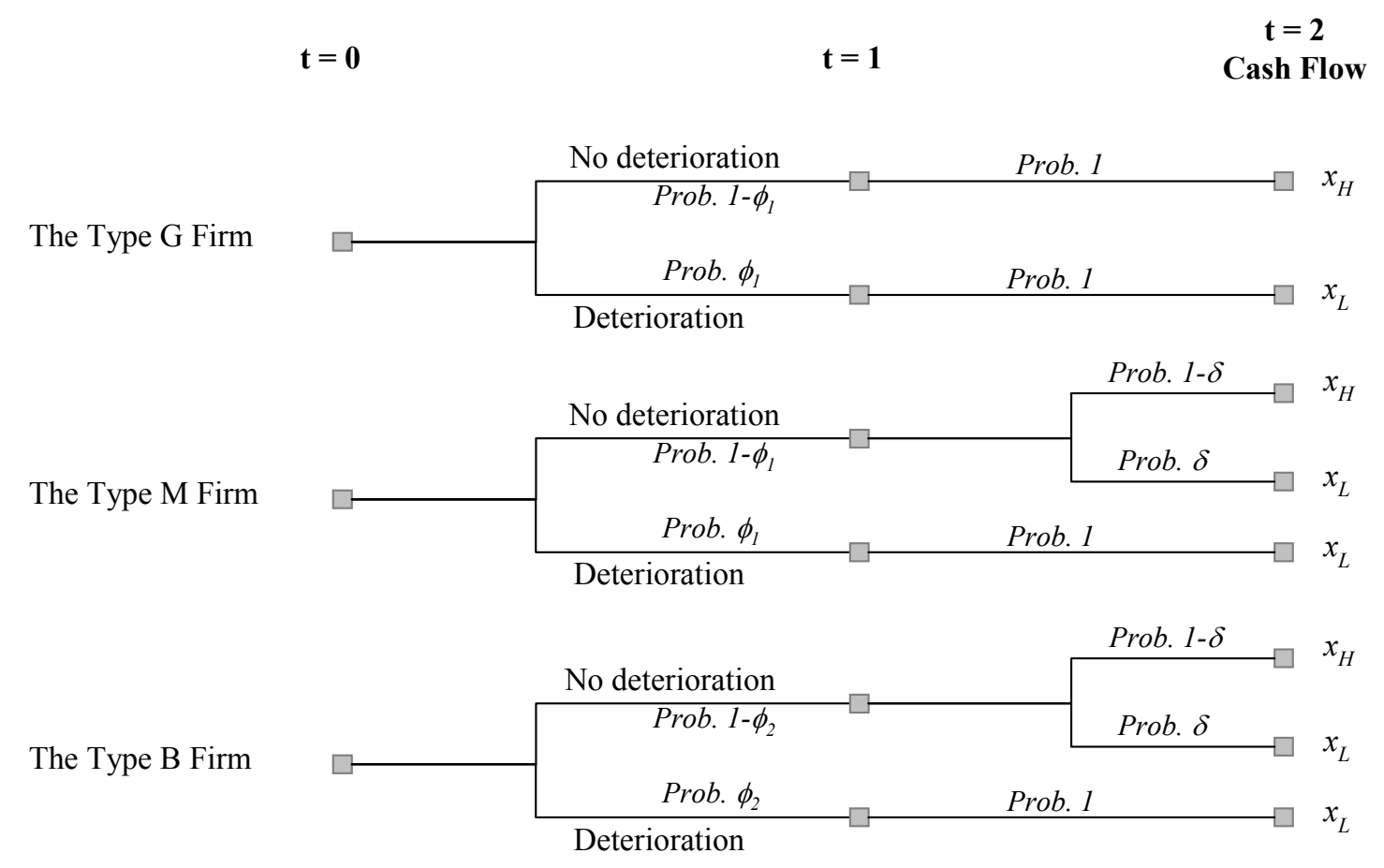

Figure 2: Cash Flow Structure for the Type G, Type M, and Type B Firms

- Entrepreneur, with private information about the firm type $(\mathrm{G}$, $\mathrm{M}$, or B), chooses among debt, ordinary convertibles, mandatory convertibles, or equity to finance the new project.

- Firm invests in the new project.
- All cash flows are realized and distributed according to the sharing rules specified by the securities issued.

- All asymmetric information is resolved.

$\mathrm{t}=$

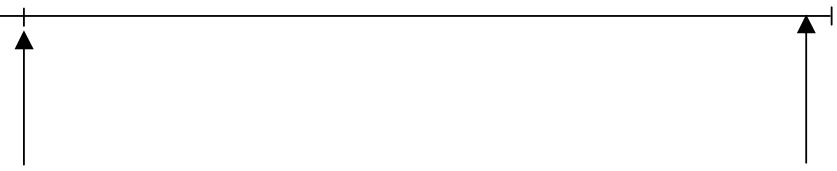

- The firm may deteriorate with a certain probability.

- Investors observe the deterioration of the firm and update their prior beliefs about the firm type.

- The firm has the right to call ordinary convertibles at this date; ordinary convertible-holders may choose to convert to equity.
- Mandatory convertibles automatically convert to equity.

Figure 3: Sequence of Events 
If the entrepreneur chooses to issue debt, he receives an amount $I$ upfront at $\mathrm{t}=0$, and promises to pay an amount $P_{d}$ to the debt holder at $\mathrm{t}=2$. If he chooses to issue ordinary callable convertible debt, he determines the face value $P_{c}$ (payable to the convertible holders at $\mathrm{t}=2$ ), the conversion ratio $n_{c}$, and the call price $K$ at $\mathrm{t}=0$. At $\mathrm{t}=1$, he has the right to redeem ("call") the convertibles at the call price $K$. If the investors convert, they receive a ratio $n_{c}$ of the total equity. If the convertible is not called, it is equivalent to a debt contract, with the firm obligated to pay $P_{c}$ to the investors at $\mathrm{t}=2$. In other words, $P_{c}$ is the sum of the principal and coupon if the convertible remains as straight debt. Alternatively, if the entrepreneur chooses to issue equity, he exchanges a fraction $n_{e}$ of the total equity to the investors for an amount $I$.

Finally, if the entrepreneur chooses to finance the amount $I$ by issuing the mandatory convertible, these convertibles mandatorily convert to the firm's equity in two periods (prior to the resolution of information asymmetry at $\mathrm{t}=2$ ). In this case, investors are promised a fraction $n_{m}$ ("the exchange ratio") of the firm's equity provided the market value of this equity exchanged is less than a "cap" amount $U_{m}$. Here, we assume $n_{m} \leq \bar{n}$, where $\bar{n}$ is the maximal possible exchange ratio, $\bar{n} \leq 1 . \bar{n}=1$ implies that the entrepreneur is willing to allow his entire equity holding in the firm to be exchanged for mandatory convertibles upon conversion; $\bar{n}<1$ implies that the entrepreneur may need to maintain a certain fraction of equity to be motivated to operate the firm or due to considerations of maintaining control in the firm. If the market value of the promised fraction of equity at $\mathrm{t}=1$ is greater than $U_{m}$, then investors receive only shares worth the amount $U_{m}$. In addition, mandatory convertible holders receive an aggregate amount $D$ of dividends over the life of the convertible. ${ }^{7} \quad$ For analytical simplicity, we will assume that the actual payment of this amount $D$ takes place at $\mathrm{t}=2 .^{8} \quad$ We also assume that $D \leq \bar{d} x_{L}$, where $\bar{d}$ is the maximum possible fraction of the firm's sure cash flow that can be paid out as dividends. ${ }^{9}$ Clearly, $\bar{d} \leq 1 ; \bar{d}=1$ implies that the firm

\footnotetext{
7 In practice, the dividend paid on mandatory convertibles is greater than that on common equity. For simplicity, we assume here that the dividend paid on common equity is zero. Thus, one can think of this dividend $D$ paid to mandatory convertible holders in our model as the dividend amount paid in excess of that paid to common equity.

8 This assumption is made only to minimize the complexity of our analysis. Since the discount rate is zero, assuming that the dividends are paid in quarterly amounts over the life of the mandatory convertible (as is the case in practice) is equivalent to a single payout at $t=2$, and will not change the nature of our results.

9 We use the term dividends here only to refer to sure (certain) cash flows proposed to investors, which is why we assume that dividends can at most equal $x_{L}$ (which happens only when $\bar{d}=1$ ). We will see later that it is the sure cash flow promised to investors that is important in the design of mandatory convertibles. Of course, in practice, firms can promise additional (uncertain) cash flows to investors over and above this amount. But investors see this as no different from other cash flows
} 
is free to pay out its entire cash flow to the investors when the cash flow realized is low, and $\bar{d}<1$ implies that the firm needs part of its realized cash flows to cover other operational expenses or implement other projects. We will show later that both the cap $U_{m}$ and the dividends paid $D$ of the mandatory convertible are determined endogenously in equilibrium.

If straight debt is issued by the entrepreneur or if ordinary convertibles are issued and the firm does not convert at $\mathrm{t}=1$ (in which case, the convertible is equivalent to a debt contract), costly financial distress may occur at $\mathrm{t}=2$. If the firm's cash flow at this date is not sufficient to pay the promised payment to the debt holders in full, the firm will be forced to declare bankruptcy. In this case, an exogenous deadweight cost $C>0$ is imposed on the entrepreneur. Remember that since $x_{L}<I<x_{H}$, bankruptcy occurs if and only if the cash flow at $\mathrm{t}=2$ turns to be low. Thus, the ex-ante (time 0 ) probability of bankruptcy is the same as the ex-ante probability of earning a low cash flow, which is $\phi_{1}$ for a type G firm, $\phi_{1}+\delta\left(1-\phi_{1}\right)$ for a type M firm, and $\phi_{2}+\delta\left(1-\phi_{2}\right)$ for a type B firm.

Of the above menu of contracts, the security actually issued by the firm will be determined in equilibrium: i.e., not all securities will be offered in all situations. We assume that the firm first chooses the security to be issued from the above menu (at $\mathrm{t}=0$ ). Further, in the case where an ordinary convertible is issued, the firm chooses at $\mathrm{t}=1$ whether or not to force conversion by calling the convertible; also, investors choose whether or not to convert these convertibles to equity at this date.

\subsection{The Objective of the Firm and Outside Investors}

The firm's objective is to maximize the expected long-term $(t=2)$ value of the equity held by the entrepreneur (or equivalently, the expected total cash flows of the project), net of the any costs associated with the external financing of the amount $I$. The firm has four options to finance the new project: straight debt, conventional convertibles, mandatory convertibles, or equity. Thus, at $\mathrm{t}=0$, the firm strategically chooses the type of security and then price the security optimally to maximize his objective. And at $\mathrm{t}=1$, in the case of ordinary convertibles, the firm chooses to execute the conversion only when the equity foregone

available at $\mathrm{t}=2$. We therefore choose to refer only to the sure cash flow promised to investors as dividends, clubbing all uncertain cash flows available to investors together as the "distribution of residual project cash flows" at $\mathrm{t}=2$. 
to exchange the convertibles is less than the sum of the fixed payment promised by the convertibles and the potential bankruptcy cost.

The investors' objective is to maximize the sum of the expected long-term value (at $t=2$ ) of equity held by them and the cash payment paid by the firm at $t=2$. Thus, holders of ordinary convertibles choose to convert to the equity only when the value of equity obtained through the exchange exceeds the fixed payment promised by the convertibles.

\section{The Equilibrium}

Definition of equilibrium. An equilibrium in this model consists of (i) the firm's choice at $\mathrm{t}=0$ about the security to be issued to the investors (including the terms of the security such as fixed-payment promised to be paid at $\mathrm{t}=2$, ratio of the equity to be exchanged in the case of convertibles and equity, the cap in the case of mandatory convertibles, etc.); (ii) a choice by the investors on whether to convert or not in the case of the ordinary convertibles. Each of the above choices by the firm and by the investors should satisfy the following requirements: (a) the choice of each type of firm maximizes his objective, given his equilibrium belief about the choice of the other party; (b) the beliefs of all three types of firm are rational, given the equilibrium choice of the others; along the equilibrium path, these beliefs are formed using Bayes' rule; (c) we restrict the equilibrium beliefs as well as the beliefs of investors in response to off-equilibrium moves by any type of firm to be such that they satisfy the Cho-Kreps intuitive criterion (see Cho and Kreps (1987)); (d) whenever there are multiple equilibria satisfying the Cho-Kreps intuitive criterion, the prevailing equilibrium is that one where the higher type firm issues the security giving a higher value of its objective, with priority given to the payoff of the type $\mathrm{G}$ over the type $\mathrm{M}$ and that of the type $\mathrm{M}$ over the type $\mathrm{B} .{ }^{10}$ Thus, the equilibrium concept we use is that of the Perfect Bayesian Equilibrium (PBE) (requirement (a) and (b)), satisfying the

\footnotetext{
10 There are two possible situations with multiple Perfect Bayesian Equilibria (PBEs). If the type G firm obtains a higher value of its objective in a separating PBE compared to a fully pooling PBE, then only the separating equilibrium survives the Cho-Kreps intuitive criterion (since otherwise, the type $\mathrm{G}$ firm has an inventive to deviate while the type M and type B do not). Similarly, if the type G firm obtains a higher payoff in a partially pooling PBE compared to a fully pooling PBE, then the fully pooling PBE is again eliminated by Cho-Kreps. Then, the only situations when there are multiple PBEs satisfying Cho-Kreps is when the type $\mathrm{G}$ firm obtains a higher payoff in a fully pooling PBE compared to a partially pooling (where only the type $\mathrm{M}$ and type B pool) or separating PBE; or the type M firm obtains a higher payoff in a partially pooling PBE compared to a separating PBE. Our condition (d) applies only in the last two situations. Note that condition (d) is similar in spirit to the notion of "efficient" PBE applied by Milgrom and Roberts (1986) to choose among multiple equilibria.
} 
additional requirements imposed by condition (c) and (d).

In the following analysis, we define $a \equiv \frac{x_{H}}{x_{L}}$. Thus, $a$ can be viewed as a factor measuring the degree of asymmetric information in the market: the larger the $a$, the greater the degree of asymmetric information. Also, we assume throughout that the deadweight cost of bankruptcy, $C$, is a constant and greater than a certain minimum level $\underline{C}$. Further, we assume that the outsiders prior that a firm is of type B, $\gamma_{3} \geq \underline{\gamma} \underline{C}$ and $\underline{\gamma}$ are explicitly defined in the appendix. ${ }^{11}$ Finally, we assume $\bar{n}=1$ and $\bar{d}=1$ in this section only; we relax this assumption in the next section. ${ }^{12}$

We first consider the case where the extent of asymmetric information in the capital market is high, while the ex-ante probability of bankruptcy of the firm is not too large. Proposition 1 characterizes the equilibrium in this situation. ${ }^{13}$

Proposition 1 (Ordinary Convertibles in a Separating Equilibrium) If the probability of deterioration of the type $G$ and the type $M$ firms $\phi_{1}$ is smaller than a certain threshold value $\phi$, or the extent of asymmetric information is large so that $a \geq \bar{a}$, then the equilibrium is separating and involves the following:

The type G firm: It issues straight debt at $t=0$, which has a face value $P_{d}=\frac{I-\phi_{1} x_{L}}{1-\phi_{1}}$ and matures at $t=2$.

The type $M$ firm: It issues a ordinary convertible at $t=0$, with a call price $K, x_{L}<K<I$, a face value $P_{c}>x_{L}$, which is convertible to a fraction $n_{c}=\frac{I-\phi_{1} x_{L}}{\left(1-\phi_{1}\right)\left[\delta x_{H}+\delta x_{L}\right]}$ of the firm's equity. It calls back the convertible at time 1 , if its conversion value at that time is below the call price $K .^{14}$

The type $B$ firm: At time 0 , it raises the amount $I$ by issuing new equity which will equal a fraction $n_{e}=\frac{I}{\left[(1-\delta)\left(1-\phi_{2}\right) x_{H}+\left(1-(1-\delta)\left(1-\phi_{2}\right)\right) x_{L}\right]}$ of the firm's total equity outstanding.

Recall that the ex ante probability of the low cash flow (i.e., bankruptcy if debt is issued) for the type G and type $\mathrm{M}$ firms is a function of both the probability of deterioration $\phi_{1}$ and the probability of the low cash flow in the event of no deterioration ( 0 for the type $\mathrm{G}$ firm and $\delta$ for the type $\mathrm{M}$ ). The above proposition thus states that, if the ex ante probability of bankruptcy of the two types of firms is low enough, or the extent of asymmetric information they face is high enough, these two types of firms find it optimal to distinguish

\footnotetext{
11 This parameter assumption merely means to rule out other equilibria, e.g., a partially pooling equilibrium in which the type $\mathrm{G}$ and the type $\mathrm{M}$ firms issue straight debt and the type B firm issues equity. Since our focus in this paper is on mandatory and ordinary convertibles, we choose not to describe these equilibria here. Details of such equilibria are available to interested readers upon request.

12 Note that this assumption in this section affects the range of the parameters in which various equilibria occur but will not change the qualitative nature of these equilibria.

13 This equilibrium is similar to Stein (1992). While the ordinary convertible is not the focus of our paper, we choose to present this proposition since it serves as a basis for our analysis on the choice between ordinary convertibles and mandatory convertibles,

14 The conversion value of a convertible is defined as the market value of the equity obtained upon conversion.
} 
themselves from the type B firm (and from each other) by issuing straight debt and ordinary convertible debt respectively. The type B firm, on the other hand, does not find it optimal to mimic the type $\mathrm{M}$ and type $\mathrm{G}$ firm by issuing similar securities since its probability of bankruptcy is greater than the above two types. It therefore funds its project by issuing equity, thereby fully revealing its type as well. We now discuss in detail the optimization problem faced by each type of firm in choosing the security to issue in equilibrium. ${ }^{15}$

\section{The Type G Firm's Problem}

The type $\mathrm{G}$ firm issues debt instead of the other securities since it wants to distinguish itself from the type $\mathrm{M}$ and the type $\mathrm{B}$ firms. The type $\mathrm{M}$ and type $\mathrm{B}$ firms have an incentive to mimic the type $\mathrm{G}$ by issuing debt because, if they could be perceived as the type G, their securities would be overvalued. However, in equilibrium, they choose not to do so since they know that, if they pool, they are more likely to incur a bankruptcy cost compared to the case where they don't pool. Such a greater expected bankruptcy cost exceeds the benefit of mimicking (arising from the overpricing of the securities) to the type $\mathrm{M}$ and type B. Similar to the type M and type B, the type G also may incur a bankruptcy cost with some probability if it issues debt. However, issuing debt allows the type $\mathrm{G}$ to separate itself from the type $\mathrm{M}$ and type $\mathrm{B}$, thus avoiding the under-valuation of its security which would arise if it pooled with the other two types. Further, the extent of such under-valuation faced by the type $\mathrm{G}$ is large as the extent of asymmetric information faced by the firm in the security market is large. Thus, when the probability of bankruptcy of the type $\mathrm{G}$ is small enough, or when the extent of asymmetric information it faces in the security market is large enough (so that the benefit of separation from the other types is large enough), then the type G firm prefers to issue debt in equilibrium.

In summary, the type G firm's decision to issue debt in equilibrium arises from the following optimization problem:

$$
\operatorname{Max} \quad \Pi_{G}=\left(1-\phi_{1}\right)\left(x_{H}-P_{d}\right)-\phi_{1} C,
$$

\footnotetext{
15 Outside investors: If the firm issues straight debt, they infer that the firm is of type G with probability 1 . If the firm issues a ordinary convertible, they infer that the firm is of type $\mathrm{M}$ with probability 1 . They convert the convertibles to equity at $\mathrm{t}=1$. If the firm issues equity, they infer that the firm is of type B with probability 1 .
} 
subject to the following incentive compatibility (IC) constraints and the break-even constraint:

$$
\begin{aligned}
\Pi_{B} & =\left[(1-\delta)\left(1-\phi_{2}\right) x_{H}+\left(1-(1-\delta)\left(1-\phi_{2}\right)\right) x_{L}\right]\left(1-n_{e}\right) \\
& \geq \Pi_{B \mid G}=(1-\delta)\left(1-\phi_{2}\right)\left(x_{H}-P_{d}\right)-\left[1-(1-\delta)\left(1-\phi_{2}\right)\right] C, \\
\Pi_{M} & =\left(1-\phi_{1}\right)\left[(1-\delta) x_{H}+\delta x_{L}\right]\left(1-n_{c}\right)-\phi_{1} C \\
& \geq \Pi_{M \mid G}=(1-\delta)\left(1-\phi_{1}\right)\left(x_{H}-P_{d}\right)-\left[1-(1-\delta)\left(1-\phi_{1}\right)\right] C ; \\
I & \leq \phi_{1} x_{L}+\left(1-\phi_{1}\right) P_{d} .
\end{aligned}
$$

Here, the IC constraint (2) guarantees that the type B firm will issue the equity in equilibrium instead of issuing debt. $\Pi_{B}$ is the value of equity owned by the entrepreneur in the type B firm if the type B does not mimic. $\Pi_{B \mid G}$ is the expected cash flow to the entrepreneur if the type B mimics the type $\mathrm{G}$ by issuing debt. It equals the residual cash flow after paying $P_{d}$ to the investors at $\mathrm{t}=2$, net of the potential bankruptcy cost, $\left[1-(1-\delta)\left(1-\phi_{2}\right)\right] C$. Similarly, the IC constraint (3) guarantees that the type M firm will issue the conventional convertibles in equilibrium instead of issuing debt. Here, $n_{c}$ is the ratio of the total equity to exchange for the convertibles when the convertibles are redeemed at $\mathrm{t}=1 ; \Pi_{M}$ is the expected cash flows to the entrepreneur if the type $\mathrm{M}$ issues the ordinary convertibles, which equals the value of equity after the redemption of the convertibles net of the expected bankruptcy cost, $\phi_{1} C . \Pi_{M \mid G}$ is the expected cash flow to the entrepreneur if the type $\mathrm{M}$ mimics the type $\mathrm{G}$ by issuing the debt. It equals the residual cash flow after paying the investors at $\mathrm{t}=2$ net of the potential bankruptcy cost, $\left[1-(1-\delta)\left(1-\phi_{1}\right)\right] C$. Finally, constraint (4) ensures that the promised payment to the investors at $\mathrm{t}=2, P_{d}$, should be such that investors at least break-even from their investment in the type G firm.

\section{The Type M Firm's Problem}

As discussed before, the type M firm chooses to separate itself from the type B by issuing convertible debt, rather than issuing equity and pooling with the type B. Such pooling would result in the type M's securities being undervalued, with the extent of under-valuation increasing in the extent of asymmetric information faced by the firm in the securities market.

The type M prefers to separate itself by issuing ordinary convertible debt rather than straight debt. By 
doing so, it separates itself not only from the type B, but the type $\mathrm{G}$ firm as well, even though mimicking the type $\mathrm{G}$ would have enabled it to obtain a higher price for its securities than if it separates (since pooling with the type $\mathrm{G}$ would allow its securities to be overvalued, while separating from both type G and type B would only allow the firm's security to correctly priced). The type M chooses to issue ordinary convertibles rather than straight debt due to the fact that issuing convertibles allows it to reduce the probability of bankruptcy, since, in the event the firm does not deteriorate at time 1, the firm's share price goes up at that time, so that the firm is able to force conversion to equity by calling back the convertible, thereby avoiding incurring bankruptcy costs in this scenario. Note, however, that issuing ordinary convertibles does not completely eliminate the probability of bankruptcy for the type $\mathrm{M}$ firm: if the firm deteriorate at time 1 , the convertible remains as long-term debt, since the conversion value of the convertible will be below the call price $K$ in this case and the firm is unable to call back the convertible. ${ }^{16}$ However, as long as the deadweight bankruptcy $\operatorname{cost} C \geq \underline{C}$ so that the reduction in expected bankruptcy costs achieved by issuing ordinary convertible debt is greater than the benefit of mimicking the type $\mathrm{G}$ by issuing straight debt, the firm prefers to issue the former, thus separating itself from the type $\mathrm{G}$ as well as the type B firm in equilibrium.

In summary, the type $\mathrm{M}$ chooses to issue ordinary convertible debt as the solution to the following optimization problem:

$$
\operatorname{Max} \quad \Pi_{M}=\left(1-\phi_{1}\right)\left[(1-\delta) x_{H}+\delta x_{L}\right]\left(1-n_{c}\right)-\phi_{1} C
$$

subject to the IC constraints of the type $\mathrm{G}$ and type $\mathrm{B}$ respectively:

$$
\begin{aligned}
& \Pi_{G} \geq \Pi_{G \mid M}=\left(1-\phi_{1}\right)\left(1-n_{c}\right) x_{H}-\phi_{1} C, \\
& \Pi_{B} \geq \Pi_{B \mid M}=\left(1-\phi_{2}\right)\left[(1-\delta) x_{H}+\delta x_{L}\right]\left(1-n_{c}\right)-\phi_{2} C ;
\end{aligned}
$$

and the break-even constraint of investors:

$$
n_{c}\left(1-\phi_{1}\right)\left[(1-\delta) x_{H}+\delta x_{L}\right]+\phi_{1} x_{L} \geq I
$$

\footnotetext{
16 A deteriorated firm, whether it is type $\mathrm{M}$ or type $\mathrm{B}$, will not only be unable to use the call provision to force conversion, but will also be unable to use this provision to exchange the convertible for cash. Since $x_{L}<K$, the call price exceeds the market value of the firm upon deterioration, so that the firm will not be able to raise the cash at time 1 to pay the call price $K$.
} 
Here, $\Pi_{G \mid M}$ and $\Pi_{B \mid M}$ are the expected cash flows that would accrue to the type $\mathrm{G}$ and the type B firms respectively if they issue ordinary convertibles, and equal to the value of equity after the redemption of the convertibles net of their expected bankruptcy costs. ${ }^{17}$

\section{The Type B Firm's Problem}

The type B's probability of attaining the low cash flow $x_{L}$ is significantly greater than that of the type $\mathrm{G}$ and the type $\mathrm{M}$. This means that, if it mimics the type $\mathrm{G}$ or the type $\mathrm{M}$ by issuing straight debt or ordinary convertibles, the type B firm will incur a significantly higher probability of bankruptcy compared to the above two types. Thus, as long as the deadweight cost of bankruptcy is significant (so that $C \geq \underline{C}$ ), the cost of mimicking the type $\mathrm{G}$ and type $\mathrm{M}$ is larger than the benefit of doing so (arising from the ability to overprice its securities). The type B firm therefore issues equity, revealing its type in equilibrium. In summary, the type B maximizes its objective $\Pi_{B}$ given by (2), subject to the type $G$ and type M's incentive compatibility constraints and the investors' break-even constraint.

We now study the situation where the extent of asymmetric information in the securities market is small compared to the situation characterized in proposition 1, but the ex ante probability of bankruptcy facing the firm is larger. Mandatory convertibles emerge as the security issued in equilibrium in this situation. There are two scenarios under which mandatory convertibles are issued. In the first scenario (characterized in proposition 2), the bankruptcy probability, while greater than in the situation characterized in proposition 1, is not too large. In the second scenario (proposition 3), the bankruptcy probability facing the issuing firm is larger than that in the situation characterized in proposition 2.

In the following proposition, we denote by $V_{M B}^{0}$ the expected value of a firm which issue mandatory convertibles at time 0 , in a partially pooling equilibrium where both the type $\mathrm{M}$ and type $\mathrm{B}$ firms issue mandatory convertibles (as in proposition 2); and by $V_{M B}^{1}$ the expected time 1 value of a firm which issues mandatory convertibles at time 0 , in the same partially pooling equilibrium, provided the firm does not deteriorate at time 1.

\footnotetext{
17 Note that the IC constraint of the type G firm is satisfied trivially here, since the type G firm does not benefit at all from mimicking the type M.
} 
Proposition 2 (Mandatory Convertibles in a Partially Pooling Equilibrium) If any one of the following two conditions hold: ${ }^{18}$

(a) The probability of deterioration of the type $M$ and type $G$ firms, $\phi_{1}$, is larger than a threshold value $\underline{\phi}$, and $\delta \geq \bar{\delta}$ so that the type $M$ firm's low cash flow probability is significantly larger than that of the type $G$; or

(b) The extent of asymmetric information facing the firm is moderate, so that $a \in[\underline{a}, \bar{a}]$,

then the equilibrium is partially pooling and involves the following:

The type $G$ firm: It issues straight debt at $t=0$, and pays an amount of $P_{d}=\frac{I-\phi_{1} x_{L}}{1-\phi_{1}}$ at $t=2$.

The type $M$ and the type $B$ firm: Both types of firm issue mandatory convertibles at $t=0$. Upon maturity, the convertibles will be converted to a fraction $n_{m}^{*} \geq \frac{I-x_{L}}{V_{M B}^{0}-x_{L}}$ of the firm's equity mandatorily, but the value of equity exchanged will be no greater than the cap amount $U_{m}^{*}=\frac{I-x_{L}}{V_{M B}^{0}-x_{L}} V_{M B}^{1}$. The dividends $D^{*}$ on these mandatory convertibles will be set equal to $x_{L}$.

In this equilibrium, the type $\mathrm{G}$ still prefers to issue debt and thereby distinguish itself from the type $\mathrm{M}$ and type B, while the type M firm prefers to pool with the type B by issuing mandatory convertibles. Remember that, if the type $\mathrm{M}$ were to choose to separate from the type $\mathrm{B}$, it can eliminate the potential financing cost arising from asymmetric information (i.e., the under-valuation of securities relative to their intrinsic value), but may incur a bankruptcy cost in the future. Thus, when the type M's expected bankruptcy cost is sufficiently large (as in the case $\phi_{1} \geq \underline{\phi}$ and $\delta \geq \bar{\delta}$ ), or when the extent of asymmetric information in the market is small enough (as in the case $a \leq \bar{a}$ ), the cost of separating exceeds the benefit of doing so. The type $\mathrm{M}$ therefore chooses to pool with the type B.

The type $\mathrm{M}$ will not choose to issue straight debt or ordinary convertible to pool, since these securities may cause the firm to go bankrupt at time 2 if the firm deteriorates at time 1 (recall that the type M's low cash flow probability is significantly greater than that of the type G). In contrast, in the case of mandatory convertibles, there is no such danger of bankruptcy, since conversion to equity is mandatory. Further, the type $\mathrm{M}$ prefers to issue mandatory convertibles to issuing equity as well. This is because, unlike equity, mandatory convertibles provide a "cap" on the "upside" cash flow paid to security holders, compensating them for this cap with an incremental dividend payment, $D<x_{L}$. The effect of this cap is to reduce the difference in the cash flow obtained by investors in the high and the low cash flow scenarios. This, in turn,

\footnotetext{
18 Outside investors infer that a firm is of type $G$ with probability 1 , if the firm issues straight debt. If the firm issues a ordinary convertible, they infer that the firm is of type M with probability $\frac{\gamma_{2}}{\gamma_{2}+\gamma_{3}}$ or type B with probability $\frac{\gamma_{3}}{\gamma_{2}+\gamma_{3}}$.
} 
means that the difference between the intrinsic (true) values of mandatory convertibles issued by the type $\mathrm{M}$ and type $\mathrm{B}$ firms is less than the corresponding difference in the intrinsic values of the equity issued by these two types of firms. Thus, the subsidization of the type B firm by the type $\mathrm{M}$ is lower if the type $\mathrm{M}$ issues mandatory convertibles, so that the under-valuation of the type M firm's securities due to asymmetric information is less if it issues mandatory convertibles rather than equity (in other words, the market value of mandatory convertibles is less sensitive to asymmetric information compared to that of equity).

Thus, in equilibrium, the type $\mathrm{M}$ firm maximizes:

$$
\Pi_{M}=\phi_{1}\left(1-n_{m}\right)\left(x_{L}-D\right)+\left(1-\phi_{1}\right)\left(1-\frac{U_{m}}{V_{M B}^{1}}\right)\left[(1-\delta) x_{H}+\delta x_{L}-D\right]
$$

subject to the IC constraint (9) ensuring that the type G has no incentive to mimic, and the break-even constraint of investors (10):

$$
\begin{aligned}
\Pi_{G} & \geq \Pi_{G \mid M B}=\phi_{1}\left(1-n_{m}\right)\left(x_{L}-D\right)+\left(1-\phi_{1}\right)\left(1-\frac{U_{m}}{V_{M B}^{1}}\right)\left(x_{H}-D\right), \\
I & \leq n_{m}\left(x_{L}-D\right) \frac{\gamma_{3} \phi_{2}+\gamma_{2} \phi_{1}}{\gamma_{2}+\gamma_{3}}+\frac{U_{m}}{V_{M B}^{1}}\left(V_{M B}^{1}-D\right)\left(1-\frac{\gamma_{3} \phi_{2}+\gamma_{2} \phi_{1}}{\gamma_{2}+\gamma_{3}}\right)+D .
\end{aligned}
$$

Here, $\Pi_{G}$ is given in (1) and $\Pi_{G \mid M B}$ is the cash flow accruing to the type $\mathrm{G}$ if it mimics the type $\mathrm{M}$ and type $\mathrm{B} ; \frac{\gamma_{3} \phi_{2}+\gamma_{2} \phi_{1}}{\gamma_{2}+\gamma_{3}}$ is the probability of deterioration at $\mathrm{t}=1$ for the firm issuing mandatory convertibles; $n_{m}\left(x_{L}-D\right)$ is the value of equity received by the investors if the firm deteriorates; and $\frac{U_{m}}{V_{M B}^{1}}\left(V_{M B}^{1}-D\right)$ is the value of the equity received by the investors if the firm does not deteriorate.

In equilibrium, the type $\mathrm{G}$ firm still chooses to issue debt and separate from the type $\mathrm{M}$ and type $\mathrm{B}$, since, as long as $\delta \geq \bar{\delta}$, its benefit from separating, namely, avoiding the under-valuation of its securities due to asymmetric information, is greater than the cost of doing so (namely, incurring a bankruptcy cost with a certain probability). Recall that, the bankruptcy (low-cash-flow) probability of the type G is always lower for the type $\mathrm{G}$ than for the type $\mathrm{M}$, so that the expected cost of issuing debt is always lower for the type $\mathrm{G}$ than for the type M. At the same time, since $\delta \geq \bar{\delta}$, the difference in the low cash flow probability between the type $\mathrm{G}$ and type M (as well as the type B) firm is significant. Therefore, the difference in the intrinsic values of these types of firms is large enough that pooling with the other two firm types imposes large costs 
on the type $\mathrm{G}$ firm. As a result, the type $\mathrm{G}$ firm finds it advantageous to separate from the other firm types by issuing debt.

In the following proposition, we denote by $V_{G M B}^{0}$ the expected value of a firm at $\mathrm{t}=0$ if all three types of firms pool by issuing mandatory convertibles at time 0 ; and by $V_{G M B}^{1}$ the expected value of a firm at $\mathrm{t}=1$ if all three types issue mandatory convertibles at time 0 , and the firm does not deteriorate at time 1 .

Proposition 3 (Mandatory Convertibles in a Fully Pooling Equilibrium) If any one of the following two conditions hold:

(a) If the probability of deterioration of the type $M$ and type $G$ firms, $\phi_{1}$, is larger than a certain threshold value $\bar{\phi}$, or if $\delta<\bar{\delta}$, so that the type $M$ and type $G$ firms' low cash flow probabilities are not too far apart; or

(b) If the extent of asymmetric information facing the firm is small enough, so that a $\leq \underline{a}$.

then all three types of firms issue mandatory convertibles at $t=0$. Upon maturity, the convertibles will be converted to a fraction $n_{m}^{*} \geq \frac{I-x_{L}}{V_{G M B}^{0}-x_{L}}$ of the firm's equity mandatorily, with the value of the equity exchanged subject to the cap amount $U_{m}^{*}=\frac{I-x_{L}}{V_{G M B}^{0}-x_{L}} V_{G M B}^{1}$. The dividends $D^{*}$ on these mandatory convertibles will be set equal to $x_{L} \cdot{ }^{19}$

When $\phi_{1} \geq \bar{\phi}$, the probability of bankruptcy of the type $G$ is large enough that the cost to the type $G$ of separating from the type $\mathrm{M}$ and the type $\mathrm{B}$ (and thus ensuing that it is correctly valued in the securities market) is overwhelmed by the expected bankruptcy cost it incurs by issuing debt. At the same time, if $\delta<\bar{\delta}$, the difference in the low cash flow probability between the type $\mathrm{G}$ and type M firms is small enough so that their intrinsic values are also close. This, in turn, means that the cost to the type G of pooling with the type $\mathrm{M}$ is not too large. As a result, the type $\mathrm{G}$ firm finds it advantageous to pool with the type $\mathrm{M}$ and the type B by issuing mandatory convertibles, rather than separating from the other two types by issuing debt. Further, the type $\mathrm{G}$ firm prefers to issue mandatory convertibles rather than equity to pool with the other two types. The intuition underlying this preference is the same as that discussed in detail in the context of the type $\mathrm{M}$ pooling with the type $\mathrm{B}$ in the previous proposition, and arises from the fact that the cap of the mandatory convertible makes its market value less sensitive to asymmetric information than that of equity. Thus, the type G maximizes:

$$
\Pi_{G}=\left(1-n_{m}\right) \phi_{1}\left(x_{L}-D\right)+\left(1-\phi_{1}\right)\left(1-\frac{U_{m}}{V_{G M B}^{1}}\right)\left(x_{H}-D\right)
$$

19 Outsiders' beliefs regarding the probability of the firm types remain unchanged. 
subject to the break-even constraint of investors:

$$
n_{m}\left(x_{L}-D\right) \operatorname{Prob}(\text { deterioration })+\frac{U_{m}}{V_{G M B}^{1}}\left(V_{G M B}^{1}-D\right) \operatorname{Prob}(\text { no deterioration })+D \geq I .
$$

The type M's problem is similar to that discussed under the previous proposition; it also prefers to pool with the type $\mathrm{G}$ and the type $\mathrm{B}$ in equilibrium by issuing mandatory convertibles, for the reason discussed under proposition 2 .

Proposition 4 (Announcement Effects of Mandatory Convertibles) The abnormal equity return upon announcement of an issue of mandatory convertibles is zero or negative. In particular, when mandatory convertibles are issued as part of a fully pooling equilibrium, the abnormal equity return upon announcement of issuing mandatory convertibles is zero; it is negative when mandatory convertibles are issued as part of a partially pooling equilibrium. ${ }^{20}$

As we saw before, mandatory convertibles are issued as part of either a fully pooling or a partially pooling equilibrium. In the case of a fully pooling equilibrium, no information about firm type is conveyed to the market by the issue of a mandatory convertible, so that the announcement effect is zero. In the case of a partially pooling equilibrium, only the type $\mathrm{M}$ and type B issue mandatory convertibles, so that the market re-values the firm (and its equity) downward to reflect this new information (recall that the market value of the firm prior to the issue would be the average of the values of the type $G$, type $M$ and type $B$ firms).

\section{Equilibrium Design of Mandatory Convertibles}

In this section, we will analyze in detail the equilibrium design of mandatory convertibles. Due to space considerations, we discuss here only the case of a fully pooling equilibrium. However, the analysis is similar in the case of a partial pooling equilibrium. ${ }^{21}$ In this section, we relax our earlier assumption that $\bar{n}=1$ and $\bar{d}=1$; we now allow for $\bar{n} \leq 1$ and $\bar{d} \leq 1$.

Proposition 5 (Equilibrium Design of Mandatory Convertibles) In a fully pooling equilibrium where all three types of firms issue mandatory convertibles:

(a) The type $G$ firm sets the exchange ratio $n_{m}$ such that $n_{m}^{*}=\bar{n}$ (i.e., the highest possible); the dividend $D$ such that $D^{*}=\bar{d} x_{L}$ (the highest possible); and the cap on the mandatory convertible $U_{m}^{*}$ is such that it is the lowest possible.

\footnotetext{
${ }^{20}$ It can be shown that, when $\gamma_{3}<\bar{\gamma}$, the announcement of issuing ordinary convertibles results in a negative abnormal equity return upon announcement of the issue. Given ordinary convertible is not the focus of our paper, we choose not to discuss this in detail.

21 Details of this analysis is available to interested readers upon request.
} 
(b) $U_{m}^{*}$ is a function of $\bar{n}$ and $\bar{d}$ (given in the appendix). It is decreasing with $\bar{d}$ and $\bar{n}$.

(c) In particular, if $\bar{d}=1$ and $\bar{n}=1$, then $D^{*}=x_{L}$, and $U_{m}^{*}=V_{G M B}^{1} \frac{I-x_{L}}{V_{G M B}^{1}-x_{L}}$, and $n_{m}^{*} \geq \frac{I-x_{L}}{V_{G M B}^{1}-x_{L}}$.

In the fully pooling equilibrium, the type G firm designs the mandatory convertible optimally to minimize its cost of pooling with the type $\mathrm{M}$ and the type B firms. The pooling cost arises because investors are not aware of the type of the firm and thus price the firm according to their prior beliefs. Therefore, to minimize this pooling cost, the mandatory convertible is designed to be minimally affected by the asymmetric information in the securities market. This is accomplished by lowering the cap $U_{m}$ of the mandatory convertible and raising the exchange ratio $n_{m}$. When this is done, the difference in the expected payment to investors in the high and the low cash flow scenarios is reduced. This reduces the difference between the intrinsic values of the mandatory convertibles issued by the three types of firms so that the market value of the mandatory convertible become less sensitive to the effects of asymmetric information. Of course, when the investors' upside is capped, they have to be compensated for this through a higher dividend, so that they break even on their investment in the firm (i.e., constraint (10) is satisfied). Since, as long as $D \leq \bar{d} x_{L}$, the firm is able to pay investors the promised amount with probability 1 regardless of firm type, dividends are unaffected by asymmetric information, so that the net effect of setting the cap $U_{m}$ as low as possible, and the exchange ratio $n_{m}$ and the dividend $D$ as high as possible is to minimize the sensitivity of the market value of the convertible to the effects of asymmetric information. ${ }^{22}$ In other words, lowering the cap $U_{m}$ and raising $n_{m}$ reduces the subsidization of the type $\mathrm{M}$ and the type $\mathrm{B}$ firms by the type $\mathrm{G}$, thereby reducing the extent of under-valuation of the type G firm's mandatory convertibles due to asymmetric information. In the following, we discuss a numerical example demonstrating parts (a), (b), and (c) of the above proposition. Numerical Examples: Set $\delta$, the probability of the low cash flow if there is no deterioration at $\mathrm{t}=1$, equal to 0.5 ; the probabilities of deterioration of the type $\mathrm{G}$ and $\mathrm{M}, \phi_{1}=0.5$ and that of type $\mathrm{B} \phi_{2}=0.8$; the prior

\footnotetext{
22 For analytical simplicity, we focus only on the case where $D \leq \bar{d} x_{L}$ so that the dividends are sure cash flows and therefore unaffected by asymmetric information. As long as there is no uncertainty associated with dividends, lowering the cap and increasing the dividends unambiguously reduces the sensitivity of the market value of the mandatory convertible to asymmetric information. Of course, firms can lower the cap on the mandatory convertible even more by promising investors additional (uncertain) cash flows as dividends, i.e., they can set $D>\bar{d} x_{L}$. However, in this case, the additional dividends are affected by asymmetric information, so that the effect of doing this on the sensitivity of the market value of the mandatory convertible to asymmetric information is ambiguous.
} 
beliefs $\gamma_{1}=0.5, \gamma_{2}=0.3$, and $\gamma_{3}=0.2$; the cash flows $x_{H}=\$ 100$ and $x_{L}=\$ 20$; and the investment $I=\$ 20$. Further, let $\bar{d}=0.5$ and $\bar{n}=1$. In this case, all three types of firms pool by issuing mandatory convertibles, selling it to investors at $\$ 20$, thus raising the full investment amount. The mandatory convertibles will be designed optimally such that the exchange ratio $n_{m}^{*}$ is 1 ; the cap $U_{m}^{*}$ is $\$ 31.2$; and the dividends $D^{*}$ is $\$ 10$ (thus maximizing the expected $\mathrm{t}=2$ payoff of the type $\mathrm{G}$ firm; this payoff is $\$ 27.33$ ). Consider now a second example, with $\bar{d}=0.75$, and keeping all other parameters the same as before. Then, all three types of firms would pool by issuing mandatory convertibles, optimally designed such that the exchange ratio $n_{m}^{*}=1$; the cap $U_{m}^{*}=\$ 23.68$; and the dividends $D^{*}=\$ 15$. In this case, the type G firm's expected payoff is $\$ 28.02$. Finally, consider a third example where $\bar{d}=1$, with all other parameters remaining the same as before. In this case, the equilibrium design of the mandatory convertibles issued by the firm is such that the exchange ratio $n_{m}^{*}=1$; the cap $U_{m}^{*}=\$ 15$; and the dividends $D^{*}=\$ 20$. In this case, the type G firm's expected payoff is $\$ 33.14$. Notice from the above three examples that as the cash constraint $\bar{d}$ on the firm is relaxed (so that the firm is able to pay out more and more of its time 2 lower cash flow as dividends), it optimally sets a lower and lower cap on the mandatory convertible. Further, notice that, as the firm sets a lower cap, the subsidization of the lower firm types by the type $\mathrm{G}$ firm is reduced, thus increasing the expected payoff to type $\mathrm{G}$ firm insiders.

\section{$5 \quad$ Implications and Testable Hypotheses}

Our model generates several testable implications. We will now describe three of these implications and develop several hypotheses for our empirical tests.

1. Choice between ordinary versus mandatory convertibles and the probability of bankruptcy: Our model implies that, in a sample of firms issuing either ordinary or mandatory convertibles, those firms with a larger ex-ante bankruptcy probability (on average) will issue mandatory convertibles while those with a smaller bankruptcy probability will issue ordinary convertibles. ${ }^{23} \quad$ As we saw from proposition 2 and 3 , when their bankruptcy probability is high, higher-valued firms prefer to pool with lower-valued firms by issuing

\footnotetext{
${ }^{23}$ While our model has implications for other pairs of securities as well, we focus our empirical tests a sample of firms which have chosen to issue either mandatory or straight convertibles.
} 
mandatory convertibles, for the reasons discussed under Proposition 2. In contrast, when their bankruptcy probability is low, higher-valued firms prefer to distinguish themselves from lower-valued ones by issuing other securities, such as ordinary convertibles or straight debt (as discussed under proposition 1.) Therefore, in a sample of firms issuing either mandatory or ordinary convertibles, those with a smaller ex-ante bankruptcy probability on average will issue ordinary convertibles and those with a larger bankruptcy probability will issue mandatory convertibles. This will be the first hypothesis $(\mathbf{H 1})$ we test later. We will use standard proxies for the bankruptcy probability such as the Altman's z-score to test this hypothesis: firms with a larger z-score (smaller bankruptcy probability) issue ordinary convertibles while those with a smaller z-score (larger bankruptcy probability) issue mandatory convertibles. ${ }^{24}$

2. Choice between ordinary versus mandatory convertibles and the extent of asymmetric information: In a sample of firms issuing either ordinary convertibles or mandatory convertibles, those firms facing a smaller extent of asymmetric information are more likely to issue mandatory convertibles, and those facing a greater extent of asymmetric information are more likely to issue ordinary convertibles. This implication also follows directly from proposition 1,2 , and 3 . This will be the second hypothesis (H2) we test later. To test this hypothesis, we will make use of standard proxies for asymmetric information such as firm size, number of analysts following a firm, standard deviation of analysts forecasts, forecast error, etc. ${ }^{25}$

3. The announcement effect of issuing mandatory convertibles: The abnormal equity return upon the announcement of the issue of mandatory convertibles is zero (in a fully pooling equilibrium) or negative (in a partially pooling equilibrium). Further, this announcement effect is decreasing (i.e., is more negative), with ex-ante probability of bankruptcy of the issuing firm on average. The first implication above follows directly from proposition 4 . The second implication follows from proposition 2 and 3 . We know from these propositions that as the difference in the ex-ante bankruptcy probability between higher and lower intrinsic value firms is larger, mandatory convertibles are more likely to be issued in a partially pooling

\footnotetext{
24 In the context of testing our model, we can split up the true bankruptcy probability of any given firm into two parts: a publicly observable component (common to all firm types and therefore reflecting the average bankruptcy probability across firm types) and an independent component which is private information to firm insiders. Since proxies such as the Altman's z-score are computed using only publicly available information, they will capture only the first component, namely, the average bankruptcy probability across firm types.

25 We will discuss these proxies of asymmetric information in detail in the next section.
} 
equilibrium (negative announcement effect) rather than in a fully pooling equilibrium (zero announcement effect). Further, whenever the average bankruptcy probability across firm types increases, the bankruptcy probability of lower intrinsic-value firms is likely to increase faster than that of higher intrinsic-value firms, resulting in a larger difference between the bankruptcy probabilities of higher and lower intrinsic-value firms. ${ }^{26}$ Thus, the likelihood of mandatory convertibles being issued in a partially pooling equilibrium (and therefore a more negative announcement effect) is increasing in the average ex-ante bankruptcy probability (as measured by standard proxies like the Altman's z-score). This is the third hypothesis (H3) we test later.

4. The operating performance of mandatory convertible issuers: If mandatory convertibles are issued in a fully pooling equilibrium (where all three types of firms issue mandatory convertibles) as characterized in proposition 3, then the long-term operating performance of mandatory convertible issuers should not underperform a sample of comparable non-issuers. On the other hand, if mandatory convertibles are issued as part of a partially pooling equilibrium, as characterized in proposition 2 , where only lower quality firms issue mandatory convertibles, then mandatory convertible issuers would underperform relative to a sample of comparable non-issuers in terms of long-term operating performance. ${ }^{27}$ Therefore, the fourth hypothesis (H4) we test is that the long-term operating performance of mandatory convertible issuers is not significantly different from that of a matched sample of non-issuers.

\section{Empirical Evidence}

\subsection{Data and Sample Selection}

We identify new issues of ordinary convertibles and mandatory convertibles between 1991 to 2001 from Securities Data Corporation's (SDC Platinum) New Issues Database. Our initial sample included 133 mandatory convertibles and 710 ordinary convertibles. We obtained the firm specific characteristics relating to the

\footnotetext{
${ }^{26}$ When economic conditions worsen, so that the average bankruptcy probability across firms increases, lower intrinsic value firms are likely to be affected much more than higher intrinsic value firms. Compared with lower intrinsic value firms, higher intrinsic value firms are likely to have a larger cushion which would prevent them from facing financial difficulties under a wider range of economic conditions.

27 Note that if mandatory convertible issuers indeed have private information at the time of issue about their firms' future performance, this negative prediction will be realized over the coming years in terms of poor operating performance relative to a matched sample of non-issuers.
} 
issuer's financial position from the issuer's annual report data on Compustat. ${ }^{28}$ This left us with a sample of 325 ordinary convertibles and 124 mandatory convertibles, as we had to omit those issues that we could not match to the Compustat data.

Details of each convertible issue were then collected from its prospectus; propectuses were obtained from the Global Access database. We eliminated the issues of ordinary and mandatory convertibles where the primary motive for their issuance was to obtain tax benefits or where the mandatory convertible was synthetically created by an investment bank. ${ }^{29} \quad$ Since our focus is on mandatory convertibles involving primary distribution of equity, we also eliminated 14 mandatory convertible issues where the equity that was being offered upon conversion belonged to another firm. ${ }^{30}$ After eliminating these issues, we were left with a sample of 220 ordinary convertibles and 78 mandatory convertibles.

The information asymmetry measures required for our empirical analysis were obtained from the IBES database. IBES reports a mean, median, and standard deviation of forecasts for each firm based on the analysts' estimates that are submitted that month. We also excluded from our sample those issues where data on some key variables required for our empirical analysis was missing in the Compustat and IBES databases. Finally, some observations were removed from the sample when data filtering indicated extreme values likely to be associated with data reporting or recording errors. This effectively left us with a sample of about 153 ordinary convertible and 41 mandatory convertible issues. ${ }^{31} \quad$ Our sample consists of 12

\footnotetext{
28 The annual report data from Compustat was matched in the following manner. For a given issue date we linked up that firm's annual report data for the fiscal year end immediately preceding the issue date. For example if the issue date was March 1995 and the firm's fiscal year end was December, we matched this firm to its annual report of December 1994.

29 Example of an ordinary convertible which is designed primarily to provide tax benefits to the issuer is LYONs (Liquid Yield Option Notes). The issuer receives continuous tax benefits after issuance until the holder exchanges the LYONs for shares, if it occurs. An example of mandatory convertible is the Participating Hybrid Option Note Exchangeable Securities (PHONES) which was first issued in early 1999. The economic advantages for the issuance of this security is completely driven by the potential tax benefits resulting from the taxation treatment of the structure under U.S. tax laws. Example of a synthetic mandatory convertible is the Structured Yield Products Exchangeable for Stock (STRYPES) designed by Merrill Lynch. The key element of the structure is that it does not entail an issue by the issuer whose equity underlies the transaction, instead the issue is undertaken by an investment bank or by using a special-purpose financing vehicle such as a trust.

30 A specific example of such a secondary distribution of equity in a mandatory convertible security is the issue of DECS by American Express on October 1993, which was to be mandatorily converted on October 1996 to shares of FDC common stock, which were held by American Express.

31 Our sample thus comprises of ordinary convertibles which are either debt or preferred stock and 12 variations of mandatory convertibles which convert into the equity of the firm issuing the convertible, and where the primary reason for the issue is not tax driven. Out of the ordinary convertibles in our sample, we have about 120 issues of ordinary convertible debt and about 30 issues of convertible preferred stock. In our econometric analysis we have clubbed them together and refer to them as ordinary convertibles.
} 
different variations of mandatory convertibles which have been designed and created by various investment banks. The variations of mandatory convertible securities which are present in our final sample are: ACES, DECS, EQUITY SECURITY UNITS, FELINE PRIDES, MARCS, MEDS, PEPS, PERCS, PIES, PRIDES, TAPS, and TRACES. Even though these mandatory convertible variations differ in their specific payoff structures as well as some other provisions, certain fundamental features are common to all of them, as we briefly discussed in the introduction to this paper. First, all of them mandatorily convert to equity at the maturity of the convertible (as against conversion to equity at the option of the security holder in the case of ordinary convertibles). Second, the dividend yield on them is typically higher than that on the underlying common stock. Third, all these mandatory convertibles have either a capped or limited appreciation potential compared to the underlying common stock.

The stock price information required for our empirical analysis of announcement effects related to the issuance of mandatory convertible securities, and long run abnormal stock performance of mandatory convertible issuers was obtained from the CRSP database. Thus, our sample of 220 ordinary and 78 mandatory convertibles had to satisfy an additional data requirement. They had to have data available on the CRSP database for a period of one year prior to their issue. About 200 issues of ordinary convertibles and 70 issues of mandatory convertibles met this requirement. We use the filing date of the issues as recorded by SDC as the announcement date; in nearly all the cases the first public announcement of the issues in either The Wall Street Journal, the Lexis-Nexis database, or the Dow Jones Newswire coincided with the filing date of the issues as recorded by SDC. ${ }^{32}$

\footnotetext{
32 One advantage of using the filing date as the announcement date is that we are able to keep those issues which were not reported in either The Wall Street Journal, the Lexis-Nexis database, or the Dow Jones Newswire. Prior studies which have used the registration date of securities to calculate the announcement effects are Best (1994), and Best and Best (1995) among others.
} 


\subsection{Choice between Mandatory and Ordinary Convertibles}

\subsubsection{Measurement of Information Asymmetry, Bankruptcy Probability, and Control Vari- ables}

Following Christie (1987), Krishnaswami and Subramaniam (1999), and Clarke and Shastri (2001), we use four different measures of information asymmetry in our empirical analysis. ${ }^{33}$ The first measure is the number of analysts following the firm (NUMA). Firms with higher analyst following can be expected to have a lower degree of information asymmetry. The second measure is the error in earnings forecast (FORERR).

We measure forecast error as the ratio of the absolute difference between the forecasted earnings and the actual earnings per share to the price per share at the end of the fiscal year. ${ }^{34}$ Firms with a higher forecast error are expected to have a greater extent of information asymmetry. Our third measure of information asymmetry is the standard deviation of analyst forecasts $(S T D E V)$, and our fourth measure is the coefficient of variation of analyst forecasts $(C O V A R)$, which is defined as the ratio of $S T D E V$ to the absolute value of the mean estimate for that month. Both STDEV and COVAR denote the dispersion among analysts regarding the earnings estimate of the firm for that month. Since a higher STDEV or(and) a higher COVAR represents greater disagreement among the analysts, it is associated with firms having a greater degree of information asymmetry.

Our measure of the probability of bankruptcy at the time of the security issue is constructed following MacKie-Mason (1990). We use the Z-score (ZSCR) calculated from Altman's (1968) bankruptcy prediction model as a proxy for the issuing firm's bankruptcy probability. Z-score is defined as $\left(3.3^{*} \mathrm{EBIT} / \mathrm{SALE}+\right.$ $\left.1.0^{*} \mathrm{SALE} / \mathrm{TA}+1.4^{*} \mathrm{RE} / \mathrm{TA}+1.2 * \mathrm{WC} / \mathrm{TA}+0.6^{*} \mathrm{MKVALF} / \mathrm{DT}\right)$ where $\mathrm{EBIT}$ is earnings before interest and taxes, SALE is total sales, RE is the retained earnings, WC is working capital, and DT is book value of debt. Firms with higher Z-scores have a lower probability of bankruptcy, while those with lower Z-scores have a higher probability of bankruptcy. ${ }^{35}$

\footnotetext{
${ }^{33}$ In computing the measures of information asymmetry involving analyst forecasts, we use the forecasts of these analysts in the final month of the fiscal year immediately preceeding the issue date of the convertible.

34 The mean monthly earnings forecast for the last month of that fiscal year is defined as forecasted earnings.

35 We also consider the leverage of the firm at the time of issue as an additional proxy for bankruptcy in checking the robustness of our empirical results. Leverage $(L E V G)$ is defined as DT/(TA+MKVALF- CEQ).
} 
In addition to measures for information asymmetry and bankruptcy probability, we use four control variables in our tests which may affect firms' choice between issuing ordinary versus mandatory convertible securities. We use firm size (FSZE) as our first control variable. Firm size is defined as $\operatorname{Ln}\left(100^{*}\right.$ (TA+MKVALFCEQ) where TA is the book value of total assets, MKVALF is the market value of equity of the firm at fiscal year end, and CEQ is the book value of common equity. ${ }^{36}$ However, prior literature (e.g., see Ritter, 1984) suggests that firm size may also be considered as a proxy for information asymmetry, since, more information is usually available to outsiders about larger firms, implying that larger firms should be associated with less information asymmetry. Second, we control for the market-to-book ratio of the issuing firm (MKBK), which is defined as (TA+MKVALF- CEQ)/TA. Firms with higher market-to-book ratios have more growth opportunities, and also often a higher extent of information asymmetry associated with these growth opportunities. Third, we construct a dummy variable $(S Y N D)$ to denote whether the convertible issue was syndicated or not. This variable takes the value 1 if the issue was syndicated by a group of underwriters, and 0 otherwise. While we use $S Y N D$ as a control variable, whether a security issue is syndicated or not is likely to have an effect, among other things, on the extent of information asymmetry facing the firm in the securities market. ${ }^{37}$ We also control for financial institutions in our sample that have issued ordinary or mandatory convertible securities. We construct a dummy variable (FIN) which takes the value of 1 if the issuer was a financial institution, and 0 otherwise.

\subsubsection{Univariate Analysis}

In this sub-section we discuss our empirical methodology, and present the results of our empirical tests on the choice of firms between issuing ordinary versus mandatory convertible securities, i.e., hypotheses H1 and H2. In our univariate tests, we report the differences in the mean and median firm characteristics between firms

\footnotetext{
36 We also conducted our empirical tests using alternate proxies for the firm size $(F S Z E)$ variable; $\operatorname{such}$ as $\operatorname{Ln}(T A)$ and $\operatorname{Ln}(S A L E)$. The results remain invariant to the choice of the FSZE proxy.

37 See, e.g., the analysis of Chemmanur and Fulghieri (1994), who demonstrate that as the reputation of the underwriter is greater, the more credibly he is able to communicate the firm's value to the securities market, thereby lowering the extent of information asymmetry facing the firm. It is reasonable to expect that a syndicate of investment banks serving as underwriter would have greater reputation and would therefore be able to perform this function more effectively.
} 
that issued mandatory convertibles and those that issued ordinary convertibles. ${ }^{38}$ Based on H1, we expect that firms issuing ordinary convertibles should have a higher ZSCR and lower LEVG (smaller bankruptcy probability), while firms issuing mandatory convertibles should have a relatively smaller $Z S C R$ and higher LEVG (higher bankruptcy probability). Based on our hypothesis H2, we expect that firms issuing ordinary convertibles should have a greater extent of asymmetric information, i.e., higher FORERR, STDEV, COVAR, and $M K B K$, and a lower value for NUMA, FSZE, and $S Y N D$; while firms issuing mandatory convertibles should have a smaller extent of asymmetric information, i.e., lower FORERR, STDEV, COVAR, and MKBK, and a higher value for NUMA, FSZE, and SYND. A priori we do not have any expectations about the value for FIN.

Panel A of table 1 reports the results from the univariate tests of H1. As expected, we find that the ZSCR and $L E V G$ variables are significantly different at the $1 \%$ level between the two groups, in both the $t$-test and the Wilcoxon rank-sum test. This result is thus consistent with our hypothesis H1, suggesting that firms issuing mandatory convertibles have a higher ex-ante probability of bankruptcy. Specifically, the mean $Z S C R$ for ordinary convertible issuers is four times higher than that of mandatory convertible issuers (12.02 versus 3.23), and mandatory convertible issuers on average have a $L E V G 33 \%$ higher than the $L E V G$ of ordinary convertible issuers (25.8\% versus $19.4 \%)$.

Panel B of table 1 reports the results from the univariate tests of H2. Consistent with H2, we find that NUMA is higher for firms that issued mandatory convertibles and the difference with ordinary convertible issuers is significant at the $1 \%$ level according to both the tests. Firms that issued mandatory convertibles had on average 17 analysts following them compared to 10 analysts following ordinary convertible issuers. Thus, firms issuing mandatory convertibles have more analysts following them, and hence are associated with a lower degree of information asymmetry compared to firms issuing ordinary convertibles. As predicted by $\mathrm{H} 2$, we also find that financial analysts make less error in the earnings forecasts and are also less likely to disagree with each other regarding earnings forecasts of mandatory convertible issuers. FORERR, STDEV,

\footnotetext{
38 We use the $t$-test for the difference in means and the Wilcoxon rank-sum test (z-statistic) for the difference in the distributions of the two samples of convertible issues. We also conducted a $\mathrm{Chi}^{2}$ test for the difference in medians, which is not reported in Table 1 for space reasons. The significance level of the variables remain unaltered when using the Chi ${ }^{2}$ test.
} 
and COVAR have lower means for the mandatory convertible issuers than for ordinary convertible issuers, with the difference in the mean of FORERR being significant at the $1 \%$ level. Further, FORERR and $C O V A R$ have lower medians for mandatory convertible issuers compared to ordinary convertible issuers. These results again suggest a lower degree of information asymmetry for firms issuing mandatory convertibles compared to ordinary convertible issuers.

Panel $\mathrm{C}$ of table 1 reports the univariate comparisons of the control variables. Consistent with $\mathrm{H} 2$, FSZE is higher for firms that issued mandatory convertibles and the difference with ordinary convertible issuers is significant at the $1 \%$ level according to both the tests. The average value of $F S Z E$ for mandatory convertible issuers was $22 \%$ larger than ordinary convertible issuers. Again, consistent with $\mathrm{H} 2, M K B K$ is lower for mandatory convertible issuers and the difference is significant at the $1 \%$ level in both the $t$-test and the Wilcoxon rank-sum test, suggesting that firms issuing mandatory convertibles have lower growth related information asymmetry. The average $M K B K$ for ordinary convertible issuers is 1.92 , about $36 \%$ higher than that of mandatory convertible issuers which is 1.41. Also, as predicted by H2, the syndication variable $S Y N D$, is higher for firms issuing mandatory convertibles (about $63.4 \%$ of mandatory convertible issues are syndicated compared to $21.6 \%$ of ordinary convertible issues), and the difference is also significant at the $1 \%$ level in both the tests. Only the Wilcoxon rank-sum test ( $Z$-statistic) is significant for the financial dummy $F I N$, with the $t$-test showing no difference between the ordinary and mandatory convertible issuers.

\subsubsection{Multivariate Analysis}

In our multivariate analysis, we examine which firm characteristics influence the choice of the convertible security that the firm issues, and to do so we employ a multinomial logistic regression framework. We first categorize firms according to the type of convertible security that they issued, which we obtained from the SDC database. We construct our dependent variable TYPE which takes the value of 1 if the security issued by a firm is a mandatory convertible security or 0 if the security issued is an ordinary convertible security. The independent variables used are firm specific proxies of information asymmetry, bankruptcy probability, and other control variables discussed in the preceding sub-section. The general form of the regression model 
is presented below:

$\ln \left[\frac{\operatorname{Pr}(T Y P E=1)}{1-\operatorname{Pr}(T Y P E=1)}\right]=\beta_{0}+\beta_{1}[I N F O]+\beta_{2} Z S C R+\beta_{3} F S Z E+\beta_{4} M K B K+\beta_{5} S Y N D+\beta_{6} F I N+\varepsilon$,

where $I N F O$ is the set of variables measuring the degree of information asymmetry associated with the issuing firm constructed from analysts' estimates, i.e., it consists of NUMA, FORERR, STDEV, and COVAR. Based on $\mathrm{H} 1$, we predict that the coefficient on $Z S C R$ should be negative since firms issuing mandatory convertibles should have smaller values of ZSCR (higher bankruptcy probability). Following H2, we expect that the coefficients of NUMA, FSZE, and SYND should be positive, while the coefficients of FORERR, STDEV, COVAR, and MKBK should be negative, as firms issuing mandatory convertibles should face a smaller extent of asymmetric information. A priori we do not have an expectation on the sign of the coefficient on FIN.

The results of this multivariate analysis are presented in Table 2 . In regressions 1 through 5 , we introduce the four information asymmetry measures one by one separately, together with the proxy of bankruptcy probability $Z S C R$, while controlling for FSZE, MKBK, SYND, and FIN in all the different specifications. As expected, we find that the coefficient of $Z S C R$ is negative and significant in all five regressions. We also find that the coefficients on all four information asymmetry measures have the expected signs. However, the coefficient of $N U M A$ is negative and insignificant in the first regression, which may result from the significant correlation between NUMA and FSZE. Thus, in regression 2, we exclude FSZE from the regression, and the coefficient of NUMA becomes positive and significant at the $1 \%$ level as expected. The coefficients on FORERR and COVAR are also significant at the 5\% and $10 \%$ levels respectively, while the coefficient on $S T D E V$ is insignificant.

Then, in regression 6 , we introduce all the asymmetric information proxies together. ${ }^{39}$ Our results show that the coefficient on ZSCR is negative and significant at the $10 \%$ level. This result is consistent with H1,

\footnotetext{
39 We include one measure between $S T D E V$ and $C O V A R$ in the regression as they both reflect the level of disagreement among the analysts' estimates. The results remain invariant to the choice of the variable.
} 
suggesting that firms facing a higher bankruptcy probability are more likely to issue mandatory convertibles, compared to ordinary convertibles. ${ }^{40}$ Our results also show that the coefficients on FORERR and COVAR are negative and significant at the $1 \%$ and $5 \%$ level respectively, suggesting that firms facing a lower extent of information asymmetry are more likely to issue mandatory convertibles. These results are consistent with our prediction from H2. However, we find that the coefficient on $N U M A$ is insignificant. As we discussed before, this insignificance may be caused by the multicollinearity between $N U M A$ and FSZE.

In addition, we also find the coefficient on FSZE, FIN and $S Y N D$ are significantly positive in all the specifications. These results confirm our findings in the univariate test, suggesting that firms issuing mandatory convertibles are more likely to have larger firm size, the probability of issuing a mandatory convertible rather than an ordinary convertible is greater for a financial firm, and that an issue of mandatory convertibles is more likely to be syndicated than one of ordinary convertibles. ${ }^{41}$

\subsection{Announcement Effects of Mandatory Convertibles}

In this sub-section we present the results of the average abnormal returns experienced by firms upon announcement of a mandatory convertible issue. To compute the cumulative abnormal returns for each issuer, we employ the standard event-study methodology. We obtain parameter estimates for the market model over a period of 250 trading days, starting from 296 days prior and ending on the 46th day prior to the announcement date of the convertible issue. We then calculated the cumulative abnormal returns for firm $i$ for the different event windows ranging from 3 days before to 3 days after the announcement day. For example the cumulative abnormal return of the $i^{t h}$ firm, $C A R_{i}$ for the $[-1,+1]$ event window is defined as $C A R_{i}=A R_{i,-1}+A R_{i, 0}+A R_{i,+1}$, the sum of the abnormal returns for firm $i$ for the day prior to the

\footnotetext{
40 As a robustness check we also used $L E V G$ as a proxy for the probability of bankruptcy. However, since $L E V G$ may be systematically related to information asymmetry and other firm specific characteristics in the model, we use an instrumental variable approach in endogenising $L E V G$. We then re-estimated all the regressions using endogenized $L E V G$ as the proxy for bankruptcy probability. The results are identical to those presented in Table 2 . The coefficient on $L E V G$ is positive and significant in all the regression specifications. Thus, firms having higher leverage have a higher probability of issuing mandatory convertibles.

${ }^{41}$ We have also conducted our empirical analysis separately for each category of ordinary convertibles, i.e., convertible debt and convertible preferred stock. The results obtained for each category are similar to the ones that are reported in this paper. Out of the two samples of ordinary convertibles, the results for the preferred stock sample are somewhat weaker than the debt sample. However, our hypothesis relating the information asymmetry measures and the choice between ordinary and mandatory convertibles are also supported in the preferred stock sample.
} 
announcement day, the announcement day, and the day after the announcement day.

Based on our hypothesis $\mathrm{H} 3$, we expect that the average $C A R$ for mandatory convertible issuers upon announcement of the issue (announcement effect) will be either zero (in a fully pooling equilibrium) or negative (in a partially pooling equilibrium). In order to test this hypothesis, we first conduct a $t$-test the null hypothesis that the announcement effect of mandatory convertible issuers is equal to zero. Then, we split our sample of mandatory convertible issues by their ZSCR (bankruptcy probability) at the time of announcement of the issue. We expect that issuers with high ZSCR (low bankruptcy probability) have a zero $C A R$, and issuers with low $Z S C R$ (high bankruptcy probability) have a negative $C A R$ upon the announcement of the issue.

Table 3 reports the results of the average abnormal returns experienced by firms upon announcement of mandatory convertible issues. As shown in the first column of Panel A, firms issuing mandatory convertibles on average experience $-0.7 \%$ abnormal return on the announcement date (event window [0]), and this announcement effect is significant at the $5 \%$ level. We also find that the announcement effects are insignificant in the other event windows, although the average $C A R$ in these windows is negative and around $-0.4 \%{ }^{42}$ These results are consistent with $\mathrm{H} 3$.

We then categorized mandatory convertible issuers into two groups: those with a high ZSCR (above median) and those with low ZSCR (below median). The other columns of panel A in table 3 reports the announcement effects of these two groups and the difference in the announcement effect between these two groups. We find that, in a sample of firms issuing mandatory convertibles, firms with high ZSCR (low bankruptcy probability) have on average zero (i.e., insignificant) announcement effect for all event windows, while firms with low ZSCR (high bankruptcy probability) on average have significantly negative announcement effects for all event windows except $[-3,0]$. In particular, the mean $C A R$ s for issuers with low ZSCR in event window [0], $[-1,0],[-1,+1]$, and $[-3,+3]$ are $-0.9 \%,-1.2 \%,-1.7 \%$ and $-1.9 \%$ respectively, and

\footnotetext{
42 In results not reported here we have also calculated the abnormal returns experienced upon the announcement of ordinary convertible debt issues. Firms issuing ordinary convertibles have a significantly negative announcement effect for all the event windows that we have considered. The mean $C A R$ for all ordinary convertible issuers is around $-1.1 \%$. For the first three event windows they are significantly negative at the $1 \%$ level, while for the last two they are significantly negative at the $5 \%$ level. These results are consistent with announcement effect results upon the issuance of ordinary convertibles as documented in the literature previously. See Dann and Mikkelson (1984), Eckbo (1986), and Mikkelson and Partch (1986) among others.
} 
all these $C A R \mathrm{~s}$ are significant at the $1 \%$ level. In comparison, the mean $C A R$ s for issuers with high $Z S C R$ in these event windows are $-0.6 \%, 0.4 \%, 0.5 \%$, and $0.6 \%$ respectively, and all are insignificant. Further, our results also show that the difference in the average abnormal returns between the high $Z S C R$ and low ZSCR samples is significant for event windows $[-1,0],[-1+1]$, and $[-3,+3]$ at either the $5 \%$ level or the $10 \%$ level. These results are again consistent with our hypothesis H3. They suggest that issuers with high ZSCR experience zero announcement effect, while issuers with low $Z S C R$ have significantly negative announcement effects.

In order to ensure our results on announcement effect is robust to the different methods of sample categorization, we further categorize our sample of mandatory convertible issuers into 3 groups: those with high $Z S C R$ (top $1 / 3^{r d}$ ), medium $Z S C R$ ( middle $1 / 3^{\text {rd }}$ ), and low $Z S C R$ (bottom $1 / 3^{\text {rd }}$ ). The results from this robustness check are presented in panel B of table 3. In general, in a sample of mandatory convertible issuers, the magnitude of the announcement effect is zero for the firms with high ZSCR (low bankruptcy probability) and significantly negative for the firms with low ZSCR (high bankruptcy probability), while it is mixed for the firms with medium ZSCR (medium bankruptcy probability) which is either zero or significantly negative. Specifically, in event window $[-1,0]$, the mean $C A R$ is $-1.4 \%$ for the issuers with low $Z S C R$; it is $-0.4 \%$ for the issuers medium ZSCR; and it is $0.5 \%$ for issuers with high $Z S C R$. And the $t$-statistics shows that the difference in $C A R$ between the high $Z S C R$ and the low $Z S C R$ samples in event window [-1,0] is significant at the $10 \%$ level. Thus, the results here are similar to those presented in panel A of table 3 , and are consistent with hypothesis H3.

Finally, since some mandatory convertible issuers in our sample had concurrent equity and debt issues, we conduct another robustness check of our results of $\mathrm{H} 3$ by excluding those firms that had concurrent issues. The results from this robustness check are presented in table 4. In particular, in panel A of table 4, we report the average abnormal returns of mandatory convertible issuers after excluding firms that had concurrent equity issues, and in Panel B, we exclude firms that had either concurrent equity or concurrent debt issues. As shown in table 4, after excluding concurrent issues, the announcement effect (the average $C A R \mathrm{~s}$ ) on the entire sample becomes significantly negative for most of the event windows. However, after 
we separate the sample by $Z S C R$, the results are similar to those presented in table 3 . The average $C A R$ s of firms with low ZSCR are mostly significantly negative, whereas it is mostly zero for firms with high $Z S C R$. In summary, the results presented in Tables 3 and 4 are generally consistent with our hypothesis H3 regarding the announcement effect experienced by firms issuing mandatory convertibles. ${ }^{43}$

\subsection{The Operating Performance of Mandatory Convertible Issuers}

In this sub-section we empirically study the operating performance of firms that have issued mandatory convertibles relative to a matched set of firms that have not issued mandatory convertibles. We test the predictions of our hypothesis $\mathrm{H}$, which hypothesizes that the long term operating performance of mandatory convertible issuers should be similar to that of a matched sample of non-issuers (if the securities are issued in a fully pooling equilibrium), or poorer to that of a matched sample of non-issuers (if the securities are issued in a partial pooling equilibrium). We study the operating performance in the year of issue (year 0), two years prior to the offering (years -2 , and -1 ), and two years subsequent to the offering (years +1 , and $+2) \cdot{ }^{44}$

Several additional data restrictions are present on our sample of mandatory convertibles in this part of the study. We exclude from our sample the firms with missing data, such as assets, sales, net income, and operating income, in the fiscal year prior to the offering. This reduced our sample of mandatory convertible issues to $32 .{ }^{45}$ We follow the matching algorithm suggested by Barber and Lyon (1996), and Loughran and Ritter (1997) to select the matched control firms. In the fiscal year prior to the issue, i.e., year -1, each issuing firm is matched with a Compustat listed non-issuing firm chosen on the basis of industry, asset size, and operating income. ${ }^{46}$ In particular, we match the mandatory convertible issuing firm to those firms

\footnotetext{
${ }^{43}$ As an additional robustness check we also classified the mandatory convertible issuers into four equal groups (quartiles) based on $Z S C R$. Again, we find that as $Z S C R$ increases, the announcement effects become less negative and ultimately zero. The magnitude and significance of the announcement effects also follow the same pattern as in panel B of Table 3 . Furthermore, the results of Table 3 and 4 remain unchanged even if we use $L E V G$ as a proxy for bankruptcy probability instead of $Z S C R$.

${ }^{44}$ We also studied the operating performance for two additional years subsequent to the offering (years +3 , and +4 ). We do not report the results for those two years as our sample size for those two years decreases considerably. Our results for the operating performance of mandatory convertible issuers for those two years are similar to the results presented here as well.

45 Due to our already restricted sample size, we do not eliminate multiple offerings by the same firm. However, in results not reported here we also conducted our operating performance study after eliminating subsequent offerings by the same firm, which reduced our sample to 26 mandatory convertible issuers. The results obtained are similar to the ones reported here.

${ }^{46}$ Barber and Lyon (1996) suggest matching on prior performance to account for the mean-reversion in accounting ratios.
} 
that have the same two-digit SIC code and whose asset size lies between $25 \%$ and $200 \%$ of the issuer in the year prior to the offering. These matching firms are then ranked by their year -1 operating income $(O I B D)$ relative to total assets $(A T)$. The firm with the closest $O I B D / A T$ ratio is selected as the matching firm. ${ }^{47}$

In our empirical analysis, we measure the operating performance of mandatory convertible issuers, using the following accounting ratios: profit margin, defined as net income/sales; $R O A$, defined as net income/assets; $O I B D / A T$, i.e., (operating income before depreciation + interest income)/assets; and $O I B D / S A$, i.e., (operating income before depreciation + interest income)/sales. The results are presented in Table 5 . In panel $\mathrm{A}$ and $\mathrm{B}$ of table 5, we report the medians of the operating performance measures for issuers and their matching non-issuers respectively. Our results show that the operating performance are quite similar between the issuers and the matched non-issuers one year prior to the issue. This provides evidence that we have achieved fairly precise matches, since our matching firms are selected based on the asset size and operating income at year -1 .

Panel $\mathrm{C}$ of table 5 reports the difference in the median accounting ratios between the mandatory convertible issuers and the matching non-issuers. For instance, for years 0,1 , and 2 , the median differences in profit margins between the issuer and non-issuer are $0.78 \%, 3.44 \%$, and $2.10 \%$ respectively, while the median differences in $R O A$ are $0.36 \%,-1.15 \%$, and $-1.43 \%$ respectively. Panel D of Table 5 reports the Z-statistics obtained for the Wilcoxon matched-pairs signed rank tests on the difference in operating performance between the mandatory convertible issuers and matched non-issuers from year -2 to year +2 . The Z-statistics suggest that the post-issue operating performance of issuers and non-issuers are not significantly different from each other in all the accounting ratios. These results are broadly consistent with our hypothesis H4, showing that firms issuing mandatory convertibles do not underperform a matched sample of non-issuers. ${ }^{48}$

Candidate matching firms belong to the universe of Compustat firms that have never issued a mandatory convertible security.

47 We also require that the matching firm has not issued any kind of securities within a one-month window of the mandatory convertible offer date.

48 We are unable to report the results by splitting the sample of mandatory convertible issuers by their $Z S C R$ (bankruptcy probability) as we did in the case of our analysis of the announcement effect. This is due to a drastic reduction in our sample size as the $Z S C R$ variable had missing values for a number of issuers. By doing so we would have effectively separated the firms issuing the securities in a fully pooling equilibrium from those issuing them in a partial pooling equilibrium. However, even with the very limited sample we did conduct our analysis of the operating performance after separating the issuers by their by their value of $Z S C R$ at the time of issuance of the mandatory convertible security. We find that throughout the post-issue period the medians of all the operating performance measures of mandatory convertible issuers having a high $Z S C R$ (low probability of bankruptcy) are substantially higher than that of issuers having a low $Z S C R$ (high probability of bankruptcy), which is 
Panel E of table 5 reports the Wilcoxon matched-pairs signed rank tests on the difference in the post-issue change of operating performance between the issuer and non-issuer over the post-issue period. The changes are calculated for three sub-periods measured over fiscal years -1 to $0,-1$ to +1 , and -1 to +2 . The results show that the changes are not statistically significant, which is again consistent with our hypothesis H4. ${ }^{49}$

Note that our model does not have any predictions on the operating performance of mandatory convertible issuers in the years prior to the issuance of the mandatory convertible. However, it is still interesting to note that, according to panel $\mathrm{D}$ of table 5 , mandatory convertible issuers do not underperform non-issuers in the years prior to the issue. This result indicates that firms issuing mandatory convertibles are not those which have deteriorated in performance prior to the security issue. ${ }^{50}$

\subsection{The Long-Run Stock Performance of Mandatory Convertible Issuers}

In this sub-section we present the results of long-run abnormal stock performance of mandatory convertible issuers. Our theoretical model does not have any direct predictions regarding the long-run stock performance of mandatory convertible issuers. However, as this is the first paper on mandatory convertible securities, we feel that it is important to document the long-run abnormal stock performance of mandatory convertible issuers. We estimate abnormal stock performance of mandatory convertible issuers in this paper using (a) cumulative abnormal returns, and (b) the intercept of the Fama-French time series regression.

\subsubsection{Cumulative Abnormal Returns}

We follow Loughran and Ritter (1997) in measuring long-run stock returns. We calculate the abnormal performance of the mandatory convertible issuers using cumulative abnormal returns from the announcement day of the issue till the end date of each event window. The matched firms are selected following the same algorithm which has been described in the previous sub-section. Stock returns are calculated in event time

generally consistent with H4. However, given the very limited sample size we cannot claim any statistical significance for these results.

49 This is in contrast to operating performance measures of equity issuers and ordinary convertible debt issuers which generally decline in the post issue period as documented by numerous studies in the literature. For example, for operating performance of equity issuers see Loughran and Ritter (1997), for operating performance of ordinary convertible issuers see Lee and Loughran (1998), and Lewis et. al. (2001), and for operating performance of floating-priced convertibles see Hillion and Vermaelen (2002).

50 This provides an interesting contrast to studies of other kinds of securities (e.g. floating-price convertibles) which document a deterioration in firm performance prior to the security issuance. See, Hillion and Vermaelen (2002) who document this for floating-price convertibles. 
and for four different event windows; a period of one year prior to the announcement of the issue, and for each of the three years subsequent to the announcement of the issue. In both panels in Table 6 daily returns of mandatory convertible issuers and the two benchmarks are compounded over the relevant trading days in order to calculate the cumulative return for the four different event windows.

In Table 6, Panel A compares cumulative average returns for the mandatory convertible issuers and the $C R S P$ value weighted index. ${ }^{51}$ In the year prior to the announcement of the issue the issuing firms significantly out-perform the $C R S P$ value weighted index, however in the three years following the announcement of the issue, the average $C A R \mathrm{~s}$ of the issuing firms relative to the market index are not significantly different from zero. The mean $C A R \mathrm{~s}$ for the three years are $6.49 \%, 3.50 \%$, and $-4.40 \%$ respectively. Panel B of table 6 reports the long-term abnormal return relative to a benchmark of matched non-issuing firms. It shows that, for both the year prior to the announcement, and for any event windows during the three years after the announcement of the issue, the long-term abnormal returns are not significantly different from zero. Thus the long run abnormal stock performance of mandatory convertible issuers is generally consistent with their long run operating performance. ${ }^{52}$

\subsubsection{Fama-French three factor regressions}

In order to check the robustness of our results on post-issue long term stock performance and to control for cross-sectional dependence, we also perform an intercept test based on the Fama-French (1993) three factor model. The following cross-sectional regression is run in each month $t$ :

$$
\left(R_{p t}-R_{f t}\right)=\alpha_{t}+\beta_{t}\left(R_{m t}-R_{f t}\right)+s_{t} S M B_{t}+h_{t} H M L_{t}+\varepsilon_{p t}
$$

Here, $R_{p t}$ is the return on the portfolio of mandatory convertible issuers in month $t, R_{m t}-R_{f t}$, the first factor, is the excess return on the market portfolio, calculated as the return on the market index $R_{m t}$ minus the

\footnotetext{
${ }^{51}$ We also compare the cumulative abnormal average performance of the mandatory convertible issuers relative to the $C R S P$ equally weighted index. The results are similar to the ones presented here. The abnormal performance of the issuers are not significantly different from the equally weighted index for the three years following the announcement of the issue.

${ }^{52}$ Our results on the long run abnormal stock performance of mandatory convertible issuers are substantially different from previous empirical papers in the literature that document the long-run abnormal stock performance of ordinary convertible debt issuers. Lee and Loughran (1998), Spiess and Affleck-Graves (1999) and Lewis et al. (2001) show that ordinary convertible debt issuers significantly underperform both the CRSP value weighted index and a matched sample of control firms in the years following the announcement of an ordinary convertible debt issue. Hillion and Vermaelen (2002) show that floating-priced convertibles underperform the $C R S P$ value weighted and equally weighted indices in the post- issue period.
} 
return on the risk-free asset $R_{f t}$ in month $t^{53}$ The second factor, $S M B_{t}$, is the return on a zero investment mimicking portfolio formed by subtracting the return on a large sized firm portfolio from the return on a small sized firm portfolio in month $t$, and the third factor, $H M L_{t}$, is the return on a zero investment mimicking portfolio formed by subtracting the return on a portfolio of high book-to-market stocks from the return on a portfolio of low book-to-market stocks in month $t$. In this procedure, the monthly returns of all firms in the portfolio of mandatory convertible issuers are aligned in event time $t$ with month 0 representing the issue announcement month. The intercept of the regression $\alpha_{t}$ is the estimate of the average abnormal performance in month $t$. The slope coefficients $\beta_{t}, s_{t}$, and $h_{t}$ measure the sensitivity of the portfolio of mandatory convertible issuers with respect to each factor. The average abnormal returns are estimated by averaging the $\alpha_{t}$ 's over the relevant months for each event window.

The results of the Fama-French three factor regressions are presented in Table 7. Panel A reports the results using the $C R S P$ value weighted index as the market portfolio to calculate $R_{m t}$, and Panel B reports the results using the CRSP equally weighted index as the market portfolio to calculate $R_{m t}$. In both panels, the results are presented in four different event windows from 12 months prior to the announcement date till 36 months after the announcement of the mandatory convertible issue. As can be seen from table 7, the average abnormal stock performance of mandatory convertible issuers is not significantly different from zero, for all the event windows. The average abnormal performance for the first 12 months subsequent to the issue is $0.1 \%$, for the next 12 months it is $-0.5 \%$, while for the last 12 months it is $0.3 \%$ when using the value weighted index as the market portfolio. Moreover, these results are invariant to the choice of the equally weighted or the value weighted index as the market portfolio. Thus, the results here are consistent with our results of the long run abnormal stock performance found in the previous sub-section with the $C A R$ approach, and are also consistent with the results on the long run operating performance of mandatory convertible issuers. Overall, we find that, unlike ordinary convertible debt issuers, firms issuing mandatory convertibles on average do not experience any long run abnormal stock performance subsequent to the announcement of

\footnotetext{
${ }^{53}$ Since previous literature on the three factor model argues about the appropriateness of using the equally weighted market portfolio vs. the value weighted market portfolio, we present results using both the equally and value weighted indices. For a discussion on this issue see Spiess and Affleck-Graves (1999).
} 
the issues. ${ }^{54}$

\section{Conclusion}

Mandatory convertibles are equity-linked hybrid securities that automatically convert to common stock on a pre-specified date, and which have become an increasingly popular means of raising capital in recent years. In this paper, we have presented the first theoretical and empirical analysis of mandatory convertibles in the literature. We considered a firm facing a financial market characterized by asymmetric information, and significant costs in the event of financial distress. The firm could raise capital either by issuing mandatory convertibles, or by issuing more conventional securities like straight debt, common stock, and ordinary convertibles. We showed that, in equilibrium, the firm issues straight debt, ordinary convertibles, or equity if the extent of asymmetric information facing it is more severe, but the probability of financial distress is relatively small; it issues mandatory convertibles if it faces a smaller extent of asymmetric information but a greater probability of being in financial distress. Our model provides a rationale for the three commonly observed features of mandatory convertibles: mandatory conversion, capped (or limited) capital appreciation, and a higher dividend yield compared to common stock. We also characterized the equilibrium design of mandatory convertibles. In addition to its implications for the choice of firms between mandatory convertibles and other securities, our model also has implications for the abnormal stock returns upon the announcement of mandatory convertibles, and for the post-issue operating performance of mandatory convertible issuers.

We tested the implications of our theory on a sample of firms which have chosen to issue either ordinary or mandatory convertibles, making use of commonly used proxies for asymmetric information (e.g., firm size, the number of analysts following a firm, standard deviation of analyst forecasts, analyst forecast error) and the probability of financial distress (Altman's Z-score, firm leverage at the time of issue). The evidence is consistent with the implications of our theory. In particular, we find that it is indeed firms facing a smaller extent of information asymmetry but a larger probability of financial distress that issue

\footnotetext{
${ }^{54}$ Again our results of the abnormal performance of a portfolio of mandatory convertible issuers using the Fama-French three factor model is in contrast to results obtained by previous studies on ordinary convertible debt issuers, where the abnormal returns are significantly negative. See Spiess and Affleck-Graves (1999) for ordinary convertible bonds, and Hillion and Vermaelen (2002) for floating-priced convertibles.
} 
mandatory convertibles; those facing a larger extent of information asymmetry and a smaller probability of financial distress issue ordinary convertibles. Our empirical evidence also supports the implications of our theory regarding the announcement effects of mandatory convertible issues and the post-issue operating performance of mandatory convertible issuers relative to that of a matched sample of non-issuers. We also document that mandatory convertible issuers do not exhibit long-term negative abnormal stock performance (in contrast to the negative abnormal long-term stock performance of ordinary convertible issuers that has been documented in the literature). 


\section{References}

Altman, E. I., 1968. Financial Ratios, Discriminant Analysis and the Prediction of Bankruptcy. Journal of Finance 23, 589-609.

Arzac, E. R., 1997. PERCS, DECS, and other Mandatory Convertibles. Journal of Applied Corporate Finance 10, 54-63.

Barber, B., Lyon, J., 1996. Detecting Abnormal Operating Performance: the empirical power and specification of test statistics. Journal of Financial Economics 41, 359-399.

Best, R. W., 1994. Relative Information Asymmetry as a Determinant of the Market Reaction to Corporate Financing Announcements. Journal of Economics and Finance 18 (2), 231-240.

Brennan, M., Kraus, A., 1987. Efficient Financing under asymmetric information. Journal of Finance $42,1225-1243$.

Brennan, M., Schwartz, E., 1977. Convertible bonds: Valuation and optimal strategies for call and conversion. Journal of Finance 32, 1699-1715.

Brennan, M., Schwartz, E., 1988. The case for convertibles. Journal of Applied Corporate Finance 1, $55-64$.

Chacko, G., Tufano, P., 2000. Cox Communications, Inc., 1999. Case No. 9-201-003, Harvard Business School, Cambridge, MA.

Chemmanur, T. J., Fulghieri, P., 1994. Investment Bank Reputation, Information Production, and Financial Intermediation. Journal of Finance 49, 57-79.

Christie, A., 1987. On Cross-sectional Analysis in Accounting Research. Journal of Accounting and Economics 9, 231-258.

Clarke, J., Shastri, K., 2001. On Information Asymmetry Metrics. Working Paper, Katz Graduate School of Business, University of Pittsburgh.

Constantinides, G., Grundy, B., 1989. Optimal investment with stock repurchase and financing as signals. Review of Financial Studies 2, 445-465.

Dann, L. Y., Mikkelson, W. H., 1984. Convertible Debt issuance, capital structure change and financing related information: Some new evidence. Journal of Financial Economics 13, 157-186.

Das, S., 2001. Structured products and Hybrid Securities (2nd Edition). John Wiley and Sons Ltd, New York.

Eckbo, E. B., 1986. Valuation effects of Corporate debt offerings. Journal of Financial Economics 15, 119-151.

Fama, E. F., French, K. R., 1993. Common risk factors in the returns on stocks and bonds. Journal of Financial Economics 33, 3-56.

Green, R., 1984. Investment incentives, debt and warrants. Journal of Financial Economics 13, 115136.

Harris, M., Raviv, A., 1985. A sequential signalling model of convertible debt call policy. Journal of Finance 41, 815-830.

Hillion, P., Vermaelen, T., 2002. Death Spiral Convertibles. Working Paper, INSEAD. 
Huckins, N. W., 1999. An Examination of Mandatorily Convertible Preferred Stock. The Financial Review 34, 89-108.

Krishnaswami, S., Subramaniam, V., 1999. Information Asymmetry, Valuation, and the Corporate Spin-off Decision. Journal of Financial Economics 53, 73-112.

Lee, I., Loughran, T., 1998. Performance following convertible bond issuance. Journal of Corporate Finance 4, 185-207.

Lewis, C., Rogalski, R., Seward, J., 2001. The long-run performance of firms that issue convertible debt: an empirical analysis of operating characteristics and analyst forecasts. Journal of Corporate Finance 7, 447-474.

Loughran, T., Ritter, J., 1997. The Operating Performance of Firms Conducting Seasoned Equity Offerings. Journal of Finance 52, 1823-1850.

MacKie-Mason, J., 1990. Do Taxes Affect Corporate Financing Decisions? Journal of Finance 45, 1471-1493.

Mayers, D., 1998. Why firms issue convertible bonds: the matching of financial and real investment options. Journal of Financial Economics 47, 83-102.

Merton, R. C., 1988. On the application of the continuous-time theory of finance to financial intermediation and insurance. Geneva Association Lecture, Centre Hec-Isa, France.

Mikkelson, W. H., Partch, M. M., 1986. Valuation effects of security offerings and the issuance process. Journal of Financial Economics 15, 31-60.

Milgrom, P., Roberts, J., 1986. Price and Advertising Signals of Product Quality. The Journal of Political Economy 94 (4), 796-821.

Miller, M., 1986. Financial Innovation: The last twenty years and the next. Journal of Financial and Quantitative Analysis 21, 459-471.

Morgan Stanley Dean Witter, 1998. Guide to PEPS. New York.

Nelken, I., 2000. Handbook of Hybrid Instruments. (Edited by I. Nelken). John Wiley and Sons Ltd, New York.

Ritter, J., 1984. The 'Hot Issue' Market of 1980. The Journal of Business 57 (2), 215-240.

Ross, S. A., 1989. Institutional Markets, Financial Marketing, and Financial Innovation. Journal of Finance 44 (3), 541-556.

Seasholes, M. S., Froot, K. A., 1996. Telmex PRIDES. Case No. 9-296-009, Harvard Business School, Cambridge, MA.

Spiess, K., Affleck-Graves, J., 1999. The long-run performance of stock returns following debt offerings. Journal of Financial Economics 54, 45-73.

Stein, J. C., 1992. Convertible bonds as backdoor equity financing. Journal of Financial Economics $32,3-21$.

Tiemann, J., 1989. Avon Products, Inc. Case No. 9-289-049, Harvard Business School, Cambridge, MA.

Tufano, P., Poetzcher, C., 1996. Times Mirror Company PEPS Proposal Review. Case No. 9-296-089, Harvard Business School, Cambridge, MA. 


\section{Appendix}

Proof of Proposition 1. In this proposition, the type G maximizes $\Pi_{G}$ subject to (4), (2), and (3); the type $\mathrm{M}$ maximizes $\Pi_{M}$ subject to (7), (6), and (5); and the type B maximizes $\Pi_{B}$ subject to:

$$
\begin{gathered}
n_{e}\left[(1-\delta)\left(1-\phi_{2}\right) x_{H}+\left(1-(1-\delta)\left(1-\phi_{2}\right)\right) x_{L}\right] \geq I . \\
\Pi_{G} \geq \Pi_{G \mid B}=\left[\left(1-\phi_{1}\right) x_{H}+\phi_{1} x_{L}\right]\left(1-n_{e}\right) \\
\Pi_{M} \geq \Pi_{M \mid B}=\left[(1-\delta)\left(1-\phi_{1}\right) x_{H}+\left(1-(1-\delta)\left(1-\phi_{1}\right)\right) x_{L}\right]\left(1-n_{e}\right)
\end{gathered}
$$

We first derive the conditions in which a fully separating PBE exists, assuming that (4), (7), and (A1) hold as equalities. In this case, inequality (5) is satisfied automatically. From inequality (6), we have $I-x_{L} \leq \frac{\phi_{2}\left(1-\phi_{1}\right) C}{\phi_{2}-\phi_{1}}$; from $(2), I-x_{L} \leq \frac{\left[1-(1-\delta)\left(1-\phi_{2}\right)\right]\left(1-\phi_{1}\right)}{\left(1-\phi_{1}\right)-(1-\delta)\left(1-\phi_{2}\right)} C ;$ and from $(3), I-x_{L} \leq\left(1-\phi_{1}\right) C$. Thus, (6) and (2) are satisfied as long as (3) is satisfied. Similarly, inequality (A2) is satisfied as long as (A3) is satisfied, which we can yield

$$
\phi_{1} C \leq \frac{(1-\delta)\left(\phi_{2}-\phi_{1}\right)\left(x_{H}-x_{L}\right) I}{V_{B}}
$$

where $V_{B}=(1-\delta)\left(1-\phi_{2}\right) x_{H}+\left[1-(1-\delta)\left(1-\phi_{2}\right)\right] x_{L}$.

Now we consider the situation where (4), (7), and (A1) do not hold as equality. Consider $\left(1-\phi_{1}\right) C<$ $I-x_{L}$. Then, (4) cannot be satisfied as an equality. In this case, the type G sets $P_{d}$ to satisfy (3) as an equality,

so that it over-pays investors to discourage the mimic from the type M. When $\left(1-\phi_{1}\right) C<\frac{\phi_{2}-\phi_{1}}{\phi_{2}}\left(I-x_{L}\right)$, (7) cannot be satisfied as an equality as well. In this case, the type M has to overpay investors to discourage the mimic from the type $\mathrm{B}$, and sets $n_{c}$ to satisfy (6) as an equality.

Thus, a separating equilibrium exists satisfying the definition of a PBE, i.e., part (a) and (b) in the definition of equilibrium described in section 3 when (A4) is satisfied. In equilibrium, the expected payoff to the type $\mathrm{G} \Pi_{G}^{S}=\operatorname{Min}\left[\left(1-\phi_{1}\right)\left(x_{H}-x_{L}\right)+\frac{x_{L}-I}{1-\delta}+\frac{\delta-\phi_{1}}{1-\delta} C,\left(1-\phi_{1}\right)\left(x_{H}-x_{L}\right)+x_{L}-I-\phi_{1} C\right]$; the expected payoff to the type $\mathrm{M} \Pi_{M}^{S}=\operatorname{Min}\left[\left(1-\phi_{1}\right)(1-\delta)\left(x_{H}-x_{L}\right)+\frac{\left(1-\phi_{1}\right)\left(x_{L}-I\right)}{1-\phi_{2}}+\frac{\phi_{2}-\phi_{1}}{1-\phi_{2}} C,\left(1-\phi_{1}\right)(1-\right.$ $\left.\delta)\left(x_{H}-x_{L}\right)+x_{L}-I-\phi_{1} C\right]$, and the expected payoff to the type $\mathrm{M} \Pi_{B}^{S}=\left(1-\phi_{2}\right)\left(\delta x_{H}+\delta x_{L}\right)+\phi_{2} x_{L}-I$. Alternatively, if the type $\mathrm{M}$ issues mandatory convertible to pool with the type $\mathrm{B}$, its expected payoff is 
$\Pi_{M}^{P P}$ (which we will derive in the proof of Proposition 2); if the type M issues debt to pool with the type G, its expected payoff is $\Pi_{M}^{\prime}=\operatorname{Min}\left\{(1-\delta)\left(1-\phi_{1}\right)\left(x_{H}-x_{L}\right)-\frac{(1-\delta)\left(1-\phi_{1}\right)}{1-\rho_{3}}\left(I-x_{L}\right)-\left[1-(1-\delta)\left(1-\phi_{1}\right)\right] C\right.$, $\left.\frac{\left(1-\phi_{1}\right)\left[V_{B}-I+\left(1-(1-\delta)\left(1-\phi_{2}\right)\right) C\right]}{\left(1-\phi_{2}\right)}-\left[1-(1-\delta)\left(1-\phi_{1}\right)\right] C\right\} ;^{55}$ and if the type $\mathrm{G}$ issues mandatory convertible to pool with the type $\mathrm{M}$ and type $\mathrm{B}$, its expected payoff is $\Pi_{G}^{F P}$ (which we will derive in the appendix of Proposition 3). Thus, given $C>c_{1} \equiv \frac{\gamma_{1}}{\gamma_{1}\left(1-\phi_{1}\right)+\gamma_{2}(1-\delta)\left(1-\phi_{1}\right)}\left(I-x_{L}\right)$, if $\phi_{1} \leq \phi^{\prime}$ or $a \geq a^{\prime \prime}$, then $\Pi_{G}^{S}$ and $\Pi_{M}^{S}$ are greater than the corresponding payoffs when the other securities is offered. We will show the expressions of $\phi^{\prime}$ and $a^{\prime \prime}$ in the proof of Proposition 2.

Proof of Proposition 2. In this proof, we will first proof the partially pooling equilibrium described in Proposition 2 satisfies part (a) and (b) of our definition of equilibrium, i.e., the definition of a PBE. Then, we will show it satisfies part (c) as well.

In this proposition, the type $\mathrm{G}$ maximizes $\Pi_{G}$ given in (1), subject to (4), and the following IC constraints:

$$
\begin{aligned}
& \Pi_{M} \geq \Pi_{M \mid G}=\left(1-\phi_{1}\right)(1-\delta)\left(x_{H}-P_{d}\right)-\left[1-(1-\delta)\left(1-\phi_{1}\right)\right] C, \\
& \Pi_{B} \geq \Pi_{B \mid G}=\left(1-\phi_{2}\right)(1-\delta)\left(x_{H}-P_{d}\right)-\left[1-(1-\delta)\left(1-\phi_{2}\right)\right] C,
\end{aligned}
$$

where $P_{d}=\frac{I-\phi_{1} x_{L}}{1-\phi_{1}}$. The type $\mathrm{M}$ maximizes $\Pi_{M}$ given in (8) and the type $\mathrm{B}$ maximizes $\Pi_{B}=(1-$ $\left.n_{m}\right) \phi_{2}\left(x_{L}-D\right)+\left(1-\phi_{2}\right)\left(1-\frac{U_{m}}{V_{M B}^{t=1}}\right)\left(\delta x_{H}+\delta x_{L}-D\right)$, subject to the IC constraints (9), where $V_{M B}^{1}=$ $\frac{1}{1-\rho_{2}^{\prime}}\left\{\gamma_{2}\left(1-\phi_{1}\right)\left[\delta x_{H}+\delta x_{L}\right]+\gamma_{3}\left(1-\phi_{2}\right)\left[\delta x_{H}+\delta x_{L}\right]\right\}$ and $\rho_{2}^{\prime}=\frac{\gamma_{3} \phi_{2}+\gamma_{2} \phi_{1}}{\gamma_{2}+\gamma_{3}}$ is the probability of deterioration at $\mathrm{t}=1$ for the firm issuing mandatory convertible. In addition, $n_{m}, D, U_{m}$ satisfy $(7)$ and

$$
U_{m} \geq n_{m} V_{M B}^{1}
$$

First, we assume (7) holds as equality and relax this assumption later in the proof. Thus, if we write (7) in terms of $n_{m}$ and incorporate it into $\Pi_{M}$, we have:

$$
\Pi_{M}=U_{m}\left(1-\phi_{1}\right) \frac{V_{M B}^{1}-x_{H}}{V_{M B}^{t=1}}+\left(P_{M}-I\right) \frac{\phi_{1}-\rho_{2}^{\prime}}{\rho_{2}^{\prime}}-\frac{U_{m}-V_{M B}^{1}}{V_{M B}^{t=1}} \frac{\phi_{1}-\rho_{2}^{\prime}}{\rho_{2}^{\prime}} D .
$$

$\frac{\partial \Pi_{M}}{\partial U_{m}}<0$ and $\frac{\partial \Pi_{M}}{\partial D}>0$, which, together with (A6), implies that $D^{*}=x_{L}, U_{m}=\frac{I-x_{L}}{V_{M B}^{0}-x_{L}} V_{M B}^{1}, n_{m}^{*} \geq$ $\frac{I-x_{L}}{V_{M B}^{0}-x_{L}}$, and $\Pi_{M}^{*}=(1-\delta)\left(V_{M B}^{0}-I\right) \frac{1-\phi_{1}}{1-\rho_{2}}$ where $\rho_{2}=\frac{\gamma_{2}\left(1-\phi_{1}\right) \delta+\gamma_{2} \phi_{1}+\gamma_{3}\left(1-\phi_{2}\right) \delta+\gamma_{2} \phi_{2}}{\gamma_{2}+\gamma_{3}}\left(\rho_{2}\right.$ is the probability

\footnotetext{
${ }_{55}$ This payoff to the type $\mathrm{M}$ occurs in the equilibrium when the type $\mathrm{M}$ and the type $\mathrm{G}$ issue debt to pool while the type $\mathrm{B}$ issues equity. Detail description and the derivation of this equilibirum is available upon the requsest of readers.
} 
of the firm issuing the mandatory convertible at $\mathrm{t}=0$ and earning a low cash flow at $\mathrm{t}=2$ ) and $V_{M B}^{0}=$ $\rho_{2} x_{L}+\left(1-\rho_{2}\right) x_{H}\left(V_{M B}^{0}\right.$ is the expected value at $\mathrm{t}=0$ of the firm issuing mandatory convertible. In this case, a partially pooling equilibrium exists when $\frac{\left(1-\rho_{2}\right) \phi_{1}}{\rho_{2}-\phi_{1}} C \leq I-x_{L}<\frac{1-(1-\delta)\left(1-\phi_{1}\right)}{\left(1-\phi_{1}\right)(1-\delta)\left(x_{H}-P_{d}\right)-\Pi_{M}^{*}} C$.

Now we relax the assumption on (7) we made above. Then, when $I-x_{L} \leq \frac{\left(1-\rho_{2}\right) \phi_{1}}{\rho_{2}-\phi_{1}} C$, (7) cannot hold as equality, and $P_{d}$ is set to satisfy (4) as an equality, in which case a partially pooling equilibrium still exists. Thus, there exist a partially pooling equilibrium satisfying part (a) and (b) of our definition of equilibrium when

$$
I-x_{L}<\frac{1-(1-\delta)\left(1-\phi_{1}\right)}{\left(1-\phi_{1}\right)(1-\delta)\left(x_{H}-P_{d}\right)-\Pi_{M}^{*}} C
$$

In this case, the payoff to the type $\mathrm{G}$ firm is $\Pi_{G}^{S}$, and the payoff to the type $\mathrm{M}$ firm is $\Pi_{M}^{P P} \equiv \Pi_{M}^{*}$.

Now we the condition under which the type $\mathrm{M}$ would not choose equity to pool with the type B. If equity is issued in the partially pooling equilibrium by the type $\mathrm{M}$ and type $\mathrm{B}$, then the expected payoff to the type M firm is $\left(1-\frac{I}{V_{M B}^{0}}\right)\left[(1-\delta)\left(1-\phi_{1}\right)\left(x_{H}-x_{L}\right)+x_{L}\right]$, which equals $\Pi_{M}\left(D=0, U_{m}=n_{m} V_{M B}^{1}\right)$ and less than $\Pi_{M}^{P P}=\max _{D, U_{m}, n_{m}} \Pi_{M}$

If the type $\mathrm{M}$ issues ordinary convertible, it earns a payoff of $\Pi_{M}^{S} . \Pi_{M}^{P P}<\Pi_{M}^{S}$ when $\phi_{1} C<[(1-$ $\left.\left.\phi_{1}\right)\left[\delta x_{H}+\delta x_{L}\right]+\phi_{1} x_{L}-I-(1-\delta)\left(V_{M, B}^{0}-I\right) \frac{1-\phi_{1}}{1-\rho_{2}}\right]$, i.e.,

$$
I-x_{L}>\frac{\phi_{1}\left(1-\rho_{2}\right)\left(\gamma_{2}+\gamma_{3}\right) C}{(1-\delta)\left(\phi_{2}-\phi_{1}\right) \gamma_{3}} .
$$

Under the constraint $C>\underline{C}$, (A9) can be satisfied only if $\gamma_{3} \geq \underline{\gamma} \equiv \frac{\phi_{1} \gamma_{1}\left(1-\phi_{1}\right)\left(1-\gamma_{1}\right)}{\left(\phi_{2}-\phi_{1}\right)\left(\gamma_{1} \phi_{2}+\gamma_{2}(1-\delta)\left(1-\phi_{1}\right)\right]}$. (A4) is satisfied as long as (A9) is true since $(1-\delta)\left(V_{M B}^{0}-I\right) \frac{1-\phi_{1}}{1-\rho_{2}}>\left[(1-\delta)\left(1-\phi_{1}\right)\left(x_{H}-x_{L}\right)+x_{L}\right]\left(1-n_{e}\right)$.

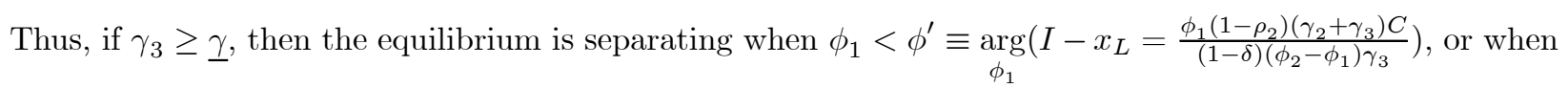
$a \geq a^{\prime \prime} \equiv \frac{(1-\delta)\left(\phi_{2}-\phi_{1}\right) \gamma_{3} x_{H}}{(1-\delta)\left(\phi_{2}-\phi_{1}\right) \gamma_{3} I-\phi_{1}\left(1-\rho_{2}\right)\left(\gamma_{2}+\gamma_{3}\right) C}$. On the other hand, when $\phi_{1} \in\left[\phi^{\prime}, \phi^{\prime \prime}\right]$ or equivalently when $a \in\left[a^{\prime}, a^{\prime \prime}\right]$, a partial pooling equilibrium occurs, where $a^{\prime}$ and $\phi^{\prime \prime}$ will be defined in the following proof.

Proof of Proposition 3. In this proof, we will first prove the fully pooling equilibrium satisfies the criteria (a) and (b) in our definition of equilibrium, and then prove it satisfies criterion (c) as well.

If mandatory convertible is issued, then the type G maximizes (11), subject to (12) and

$$
U_{m} \leq n_{m} V_{G M B}^{1}
$$


where $V_{G M B}^{1}=\frac{1}{\rho_{1}^{\prime}}\left\{\gamma_{1}\left(1-\phi_{1}\right) x_{H}+\gamma_{2}\left(1-\phi_{1}\right)\left[\delta x_{H}+\delta x_{L}\right]+\gamma_{3}\left(1-\phi_{2}\right)\left[\delta x_{H}+\delta x_{L}\right]\right\}$ and $\rho_{1}^{\prime}=\gamma_{1} \phi_{1}+\gamma_{2} \phi_{1}+\gamma_{2} \phi_{2}$ ( $\rho_{1}^{\prime}$ is the probability of firm deteriorating at $\mathrm{t}=1$ ).

If we write (12) in terms of $n_{m}$ and incorporate it into (11), we have:

$$
\Pi_{G}=U_{m}\left(1-\phi_{1}\right) \frac{V_{G M B}^{1}-x_{H}}{V_{G M B}^{1}}+\left(P_{M}-I\right) \frac{\phi_{1}-\rho_{1}^{\prime}}{\rho_{1}^{\prime}}-\frac{U_{m}-V_{G M B}^{1}}{V_{G M B}^{1}} \frac{\phi_{1}-\rho_{1}^{\prime}}{\rho_{1}^{\prime}} D .
$$

$\frac{\partial \Pi_{G}}{\partial U_{m}}<0$ and $\frac{\partial \Pi_{G}}{\partial D}>0$, which, together with (12), implies that $D^{*}=x_{L}, U_{m}^{*}=\frac{I-x_{L}}{V_{G M B}^{0}-x_{L}} V_{1}, n_{m}^{*} \geq \frac{I-x_{L}}{V_{G M B}^{0}-x_{L}}$ and $\Pi_{G}^{F P}=\Pi_{G}^{*}=\left(V_{G M B}^{0}-I\right) \frac{1-\phi_{1}}{1-\delta_{1}}$.

If equity is issued in the fully pooling equilibrium, then the expected payoff to the type G firm (1$\left.\frac{I}{V_{G M B}^{0}}\right)\left[\left(1-\phi_{1}\right) x_{H}+\phi_{1} x_{L}\right]$, where $V_{G M B}^{0}$ is the expected firm value at $\mathrm{t}=0, V_{G M B}^{0}=\left(1-\rho_{1}\right) x_{H}+\rho_{1} x_{L}$. Here, $\rho_{1}$ is the investors' belief of a pooling firm earning a low cash flow at $\mathrm{t}=2$, and $\rho_{1}=\gamma_{1} \phi_{1}+\gamma_{2}(1-$ $\left.\phi_{1}\right) \delta+\gamma_{2} \phi_{1}+\gamma_{3}\left(1-\phi_{2}\right) \delta+\gamma_{3} \phi_{2}$. This payoff equals $\Pi_{G}\left(D=0, U_{m}=n_{m} V_{1}\right)$, which is smaller than $\Pi_{G}^{F P}$ which equals $\max _{D, U_{m}, n_{m}} \Pi_{G}$. If debt is issued in the fully pooling equilibrium, the payoff to the type $\mathrm{G}$ is $\left(1-\phi_{1}\right)\left(x_{H}-\frac{I-\rho_{1} x_{L}}{1-\rho_{1}}\right)-\phi_{1} C$. If ordinary convertible is issued in the fully pooling equilibrium with call price $K \in\left(x_{L}, I\right)$, the payoff to the type $\mathrm{G}$ is $\left(1-\phi_{1}\right)\left(1-\frac{I-\rho_{1}^{\prime} x_{L}}{\left(1-\rho_{1}^{\prime}\right) x_{H}}\right) x_{H}-\phi_{1} C$. It is easy to show that $\Pi_{G}^{F P}$ is the highest among all the above payoffs as long as $C>0$. Thus, the type $\mathrm{G}$ prefers to issue mandatory convertible when pooling with both the type $\mathrm{M}$ and the type B firms.

If the type $\mathrm{G}$ firm issues debt to separate itself from the other types, it earns a payoff of $\Pi_{G}^{S}$. $\Pi_{G}^{F P} \geq \Pi_{G}^{S}$ when

$$
I-x_{L}<\frac{\left(1-\rho_{1}\right) \phi_{1} C}{\rho_{1}-\phi_{1}}
$$

Thus, if we rewrite (A12), then, when $\left.\phi_{1}>\phi^{\prime \prime} \equiv \underset{\phi_{1}}{\arg \left(I-x_{L}\right.}=\frac{\left(1-\rho_{1}\right) \phi_{1} C}{\rho_{1}-\phi_{1}}\right)$, or when $a<a^{\prime} \equiv \frac{\left(\rho_{1}-\phi_{1}\right) x_{H}}{\left(\rho_{1}-\phi_{1}\right) I-\left(1-\rho_{1}\right) \phi_{1} C}$, the type $\mathrm{G}$ prefers to issue mandatory convertible to pool with the type $\mathrm{M}$ and type $\mathrm{B}$.

Proof of Proposition 4. Before time 0 , the market value the equity of a pooling firm at $\gamma_{1}\left[\left(1-\phi_{1}\right) x_{H}+\right.$ $\left.\phi_{1} x_{L}\right]+\gamma_{2}\left[\left(1-\phi_{1}\right)\left(\delta x_{H}+\delta x_{L}\right)+\phi_{1} x_{L}\right]+\gamma_{3}\left[\left(1-\phi_{2}\right)\left(\delta x_{H}+\delta x_{L}\right)+\phi_{2} x_{L}\right]$. If a firm issues debt, the market revalues the firm at $\left(1-\phi_{1}\right) x_{H}+\phi_{1} x_{L}$. If a firm issues equity, the market values it at $\left(1-\phi_{2}\right)\left(\delta x_{H}+\delta x_{L}\right)+\phi_{2} x_{L}$. If a firm issues ordinary convertible, the market re-values it at $\left(1-\phi_{1}\right)\left(\delta x_{H}+\delta x_{L}\right)+\phi_{1} x_{L}$, which is greater than the market equity value before time 0 if $\gamma_{3}<\bar{\gamma} \equiv \gamma_{1} \frac{\delta\left(1-\phi_{1}\right)}{(1-\delta)\left(\phi_{2}-\phi_{1}\right)}$. 
Proof of Proposition 5. Let $n_{m} \leq \bar{n}, D \leq \bar{d} x_{L}$. Then following the proof of Proposition 3 , $\frac{\partial \Pi_{G}}{\partial n_{m}}>0$ for any given $D \leq x_{L}$, and $\frac{\partial \Pi_{G}}{\partial D}>0$ for any $n_{m} \leq 1$. Thus, $n_{m}^{*}=\bar{n}, D^{*}=\bar{d} x_{L}$, and $U_{m}^{*}=$ $\frac{I-x_{L}}{V_{G M B}^{0}-x_{L}} V_{G M B}^{t=1}+(1-\bar{d}) \frac{x_{L}\left[\left(1-\rho_{1}^{\prime}\right)\left(V_{G M B}^{1}-x_{L}\right)+V_{G M B}^{1}(1-\bar{n}) \rho_{1}^{\prime}\right]}{V_{G M B}^{0}-x_{L}}$. It is easy to show that $\frac{\partial U_{m}^{*}}{\partial \bar{d}}<0$ and $\frac{\partial U_{m}^{*}}{\partial \bar{n}}<0$. 


\section{Table 1}

Tests of differences in mean and median characteristics of firms issuing ordinary and mandatory convertibles. $N U M A$ is the number of analysts, FORERR is the error in analysts' forecast estimates, STDEV is the standard deviation in analysts' forecasts, COVAR is the coefficient of variation in analysts' forecasts, FSZE is the firm size, defined as $\operatorname{Ln}(100 *(\mathrm{TA}+\mathrm{MKVALF}-\mathrm{CEQ}), M K B K$ is the market-to-book ratio, defined as (TA+MKVALF$\mathrm{CEQ}) / \mathrm{TA}, \quad Z S C R$ is defined as $(3.3 * \mathrm{EBIT} / \mathrm{Sales}+1.0 *$ Sales/TA $+1.4 * \mathrm{RE} / \mathrm{TA}+1.2 * \mathrm{WC} / \mathrm{TA}+$ $\left.0.6^{*} \mathrm{MKVALF} / \mathrm{DT}\right), L E V G$ is firm leverage defined as DT/(TA+MKVALF- CEQ), $S Y N D$ is a dummy variable taking the value of 1 if the issue is syndicated and 0 otherwise, and FIN is a dummy variable which takes the value of 1 if the issuing firm is a financial firm and 0 otherwise. The results of $t$-tests for difference in means and the Wilcoxon rank-sum test (z-statistic) for the difference in distributions of the characteristics between firms issuing ordinary and mandatory convertibles are reported. $* * *, * *$, and $*$ denotes significance at the 1,5 , and 10 percent levels respectively.

\begin{tabular}{|c|c|c|c|c|c|c|}
\hline Variables & $\begin{array}{l}\text { Convertible } \\
\text { Security Type }\end{array}$ & Observations & Means & $\begin{array}{l}\text { t-statistics } \\
\text { (difference } \\
\text { in means) }\end{array}$ & Medians & $\begin{array}{l}\text { Wilcoxon rank } \\
\text { sum (Mann- } \\
\text { Whitney) test }\end{array}$ \\
\hline \multicolumn{7}{|c|}{ Panel A: Univariate comparison of bankruptcy probabilities } \\
\hline \multirow[t]{2}{*}{ Z-Score (ZSCR) } & Ordinary & 153 & 12.020 & & 3.996 & \\
\hline & Mandatory & 41 & 3.229 & $4.156^{* * *}$ & 2.342 & $3.588^{* * *}$ \\
\hline \multirow[t]{2}{*}{ Leverage $(L E V G)$} & Ordinary & 153 & 0.194 & & 0.176 & \\
\hline & Mandatory & 41 & 0.258 & $-2.710^{* * *}$ & 0.243 & $-3.008 * * *$ \\
\hline \multicolumn{7}{|c|}{ Panel B: Univariate comparison of the extent of asymmetric information } \\
\hline \multirow[t]{2}{*}{ Number of Analysts (NUMA) } & Ordinary & 153 & 10.542 & & 9.000 & \\
\hline & Mandatory & 41 & 17.244 & $-4.511 * * *$ & 18.000 & $-4.476^{* * *}$ \\
\hline \multirow[t]{2}{*}{ Forecast Error (FORERR) } & Ordinary & 153 & 0.014 & & 0.003 & \\
\hline & Mandatory & 41 & 0.005 & $2.980 * * *$ & 0.002 & 1.321 \\
\hline \multirow[t]{2}{*}{ Std. Dev. Of Estimate (STDEV) } & Ordinary & 147 & 0.092 & & 0.030 & \\
\hline & Mandatory & 41 & 0.085 & 0.359 & 0.050 & $-2.090^{* *}$ \\
\hline \multirow[t]{2}{*}{ Coeff. Of Variation of Estimate (COVAR) } & Ordinary & 146 & 0.394 & & 0.047 & \\
\hline & Mandatory & 41 & 0.208 & 1.094 & 0.046 & 0.273 \\
\hline \multicolumn{7}{|c|}{ Panel C: Univariate comparison of control variables } \\
\hline \multirow[t]{2}{*}{ Firm Size (FSZE) } & Ordinary & 153 & 7.039 & & 6.925 & \\
\hline & Mandatory & 41 & 8.600 & $-7.198 * * *$ & 8.344 & $-5.787 * * *$ \\
\hline \multirow[t]{2}{*}{ Market to Book Ratio (MKBK) } & Ordinary & 153 & 1.918 & & 1.529 & \\
\hline & Mandatory & 41 & 1.413 & $3.650 * * *$ & 1.195 & $3.340 * * *$ \\
\hline \multirow[t]{2}{*}{ Syndication Dummy (SYND) } & Ordinary & 153 & 0.216 & & 0.000 & \\
\hline & Mandatory & 41 & 0.634 & $-5.033 * * *$ & 1.000 & $-5.159 * * *$ \\
\hline \multirow[t]{2}{*}{ Financial Firm $(F I N)$} & Ordinary & 153 & 0.007 & & 0.000 & \\
\hline & Mandatory & 41 & 0.073 & -1.598 & 0.000 & $-2.660 * * *$ \\
\hline
\end{tabular}




\section{Table 2}

This table reports multinomial logit regressions relating the firm's choice of the convertible security type to various measures of information asymmetry, and the bankruptcy probability. The dependent variable $T Y P E$ takes the value of 1 if the firm issues a mandatory convertible and 0 if the firm issues an ordinary convertible. $N U M A$ is the number of analysts, FORERR is the error in analysts' forecast estimates, STDEV is the standard deviation in analysts' forecasts, COVAR is the coefficient of variation in analysts' forecasts, FSZE is the firm size, defined as $\operatorname{Ln}(100 *(\mathrm{TA}+\mathrm{MKVALF}-\mathrm{CEQ}), M K B K$ is the market-to-book ratio, defined as (TA+MKVALF$\mathrm{CEQ}) / \mathrm{TA}, \quad Z S C R$ is defined as $\left(3.3 * \mathrm{EBIT} / \mathrm{Sales}+1.0^{*} \mathrm{Sales} / \mathrm{TA}+1.4 * \mathrm{RE} / \mathrm{TA}+1.2 * \mathrm{WC} / \mathrm{TA}+\right.$ $\left.0.6^{*} \mathrm{MKVALF} / \mathrm{DT}\right), S Y N D$ is a dummy variable taking the value of 1 if the issue is syndicated and 0 otherwise, and FIN is a dummy variable which takes the value of 1 if the issuing firm is a financial firm and 0 otherwise. We introduce the different measures of information asymmetry one at a time in the regressions 1 through 5 . In regression 6 we incorporate all the measures of information asymmetry together. Due to the high correlation between FSZE and NUMA, and due to the fact that FSZE also proxies for information asymmetry, we omit FSZE in the second specification. The $z$-statistics are in parentheses and ***,**, and * indicate significance at the 1, 5, and 10 percent level respectively. Z-statistics are calculated using White's (1980) method.

\begin{tabular}{|c|c|c|c|c|c|c|}
\hline Independent Variables & $\operatorname{Reg} 1$ & $\operatorname{Reg} 2$ & $\operatorname{Reg} 3$ & $\operatorname{Reg} 4$ & $\operatorname{Reg} 5$ & $\operatorname{Reg} 6$ \\
\hline Number of Analysts (NUMA) & $\begin{array}{l}-0.005 \\
(-0.13)\end{array}$ & $\begin{array}{c}0.078 \\
(3.31)^{* * *}\end{array}$ & & & & $\begin{array}{l}-0.031 \\
(-0.81)\end{array}$ \\
\hline Forecast Error (FORERR) & & & $\begin{array}{c}-33.697 \\
(-2.50)^{* *}\end{array}$ & & & $\begin{array}{c}-37.839 \\
(-2.67)^{* * *}\end{array}$ \\
\hline Std. Dev. Of Estimate (STDEV) & & & & $\begin{array}{l}-2.238 \\
(-1.55)\end{array}$ & & \\
\hline Coeff. Of Var of Estimate (COVAR) & & & & & $\begin{array}{c}-0.267 \\
(-1.93)^{*}\end{array}$ & $\begin{array}{c}-0.269 \\
(-2.11)^{* *}\end{array}$ \\
\hline Z-Score (ZSCR) & $\begin{array}{c}-0.095 \\
(-2.03)^{* *}\end{array}$ & $\begin{array}{c}-0.131 \\
(-2.09)^{* *}\end{array}$ & $\begin{array}{c}-0.121 \\
(-1.78)^{*}\end{array}$ & $\begin{array}{c}-0.106 \\
(-2.01)^{* *}\end{array}$ & $\begin{array}{c}-0.105 \\
(-2.04)^{* *}\end{array}$ & $\begin{array}{c}-0.131 \\
(-1.72)^{*}\end{array}$ \\
\hline Firm Size (FSZE) & $\begin{array}{c}0.800 \\
(3.67)^{* * *}\end{array}$ & & $\begin{array}{c}0.748 \\
(4.97)^{* * *}\end{array}$ & $\begin{array}{c}0.799 \\
(5.02)^{* * *}\end{array}$ & $\begin{array}{c}0.823 \\
(5.04)^{* * *}\end{array}$ & $\begin{array}{c}0.939 \\
(4.08)^{* * *}\end{array}$ \\
\hline Market to Book Ratio $(M K B K)$ & $\begin{array}{l}-0.685 \\
(-1.30)\end{array}$ & $\begin{array}{l}-0.421 \\
(-0.88)\end{array}$ & $\begin{array}{l}-0.863 \\
(-1.29)\end{array}$ & $\begin{array}{l}-0.781 \\
(-1.29)\end{array}$ & $\begin{array}{l}-0.707 \\
(-1.29)\end{array}$ & $\begin{array}{l}-0.983 \\
(-1.41)\end{array}$ \\
\hline Syndication Dummy (SYND) & $\begin{array}{c}1.300 \\
(2.86)^{* * *}\end{array}$ & $\begin{array}{c}1.495 \\
(3.55)^{* * *}\end{array}$ & $\begin{array}{c}1.359 \\
(2.83)^{* * *}\end{array}$ & $\begin{array}{c}1.203 \\
(2.63)^{* * *}\end{array}$ & $\begin{array}{c}1.318 \\
(2.81)^{* * *}\end{array}$ & $\begin{array}{c}1.462 \\
(2.90)^{* * *}\end{array}$ \\
\hline Financial Firm $(F I N)$ & $\begin{array}{c}5.593 \\
(3.82)^{* * *}\end{array}$ & $\begin{array}{c}5.790 \\
(3.10)^{* * *}\end{array}$ & $\begin{array}{c}6.237 \\
(3.02)^{* * *}\end{array}$ & $\begin{array}{c}5.810 \\
(3.58)^{* * *}\end{array}$ & $\begin{array}{c}5.857 \\
(3.74)^{* * *}\end{array}$ & $\begin{array}{c}6.506 \\
(2.83)^{* * *}\end{array}$ \\
\hline Constant & $\begin{array}{c}-6.633 \\
(-4.73) * * * \\
\end{array}$ & $\begin{array}{c}-1.828 \\
(-2.52)^{* *} \\
\end{array}$ & $\begin{array}{c}-5.634 \\
(-4.16)^{* * *} \\
\end{array}$ & $\begin{array}{c}-6.240 \\
(-4.97)^{* * *} \\
\end{array}$ & $\begin{array}{c}-6.710 \\
(-5.16)^{* * *} \\
\end{array}$ & $\begin{array}{c}-6.398 \\
(-4.06)^{* * *} \\
\end{array}$ \\
\hline No. of observations & 194 & 194 & 194 & 188 & 187 & 187 \\
\hline Wald $\mathrm{Chi}^{2}$ & $45.64 * * *$ & $29.00^{* * *}$ & $44.29 * * *$ & $43.76^{* * *}$ & $43.01^{* * *}$ & $42.28 * * *$ \\
\hline Pseudo $\mathrm{R}^{2}$ & 0.351 & 0.280 & 0.384 & 0.352 & 0.363 & 0.401 \\
\hline
\end{tabular}




\section{Table 3}

This table reports the abnormal returns upon announcement of mandatory convertible issues. The abnormal returns are reported for five different event windows around the announcement date (day 0) of the security issue. In Panel A, mandatory convertible issuers are separated into two groups based on the median value of $Z$ Score $(Z S C R)$, whereas in Panel B the firms are separated into three equal groups based on the value of ZSCR. For each category of firms and for each event window the cumulative abnormal returns are then tested for significant differences from zero ( $t$-statistics in parentheses). In addition, $t$-statistics for the difference in abnormal returns between the high and low ZSCR samples of mandatory convertible issuers are also reported. $* * *, * *$, and $*$ indicate significance at the 1,5 , and 10 percent level respectively.

PANEL A

\begin{tabular}{|c|c|c|c|c|}
\hline \multirow{2}{*}{ Event Window } & \multicolumn{3}{|c|}{ Firms Issuing Mandatory Convertibles } \\
\cline { 2 - 5 } & & & & \\
& All & High ZSCR & Low ZSCR & $\begin{array}{c}t \text {-statistics (difference } \\
\text { between high and low } \\
\text { ZSCR samples) }\end{array}$ \\
\hline \hline & & & & $(0.35)$ \\
{$[0]$} & & & & $(2.21)^{* *}$ \\
{$[-1,0]$} & -0.007 & -0.006 & $(-4.20)^{* * *}$ & $(1.94)^{*}$ \\
& $(-2.22)^{* *}$ & $(-0.80)$ & -0.012 & $(0.58)$ \\
& -0.004 & 0.004 & $(-4.20)^{* * *}$ & \\
{$[-1,+1]$} & $(-1.26)$ & $(0.60)$ & -0.017 & $(1.82)^{*}$ \\
\hline
\end{tabular}

PANEL B

\begin{tabular}{|c|c|c|c|c|}
\hline \multirow[b]{2}{*}{ Event Window } & \multicolumn{4}{|c|}{ Firms Issuing Mandatory Convertibles } \\
\hline & High $Z S C R$ & Medium ZSCR & Low $Z S C R$ & $\begin{array}{c}t \text {-statistics (difference } \\
\text { between high and low } \\
\text { ZSCR samples) }\end{array}$ \\
\hline$[0]$ & $\begin{array}{l}-0.008 \\
(-0.66)\end{array}$ & $\begin{array}{c}-0.007 \\
(-2.40)^{* *}\end{array}$ & $\begin{array}{c}-0.009 \\
(-2.95)^{* *}\end{array}$ & $(0.12)$ \\
\hline$[-1,0]$ & $\begin{array}{l}0.005 \\
(0.53)\end{array}$ & $\begin{array}{l}-0.004 \\
(-0.97)\end{array}$ & $\begin{array}{c}-0.014 \\
(-3.31)^{* * *}\end{array}$ & $(1.79)^{*}$ \\
\hline$[-1,+1]$ & $\begin{array}{l}0.011 \\
(0.75)\end{array}$ & $\begin{array}{c}-0.016 \\
(-2.60)^{* *}\end{array}$ & $\begin{array}{c}-0.013 \\
(-2.73)^{* *}\end{array}$ & $(1.49)$ \\
\hline$[-3,0]$ & $\begin{array}{l}-0.002 \\
(-0.25)\end{array}$ & $\begin{array}{l}-0.001 \\
(-0.22)\end{array}$ & $\begin{array}{l}-0.006 \\
(0.43)\end{array}$ & $(0.37)$ \\
\hline$[-3,+3]$ & $\begin{array}{l}0.008 \\
(0.37)\end{array}$ & $\begin{array}{l}-0.014 \\
(-0.90)\end{array}$ & $\begin{array}{c}-0.028 \\
(-2.96)^{* *}\end{array}$ & $(1.45)$ \\
\hline
\end{tabular}




\section{Table 4}

This table reports the abnormal returns upon announcement of mandatory convertible issues, excluding concurrent equity issuers only (Panel A) and excluding either concurrent debt issuers or concurrent equity issuers or both (Panel B). The abnormal returns are reported for five different event windows around the announcement date (day 0) of the security issue. In both Panel A and Panel B we also separate the issuers into two groups based on the median value of Z-Score (ZSCR). For each category of firms and for each event window the cumulative abnormal returns are then tested for significant differences from zero. The $t$-statistics are provided in parentheses, and ***,**, and * indicate significance at the 1,5 , and 10 percent level respectively.

PANEL A

\begin{tabular}{|c|c|c|c|c|}
\hline \multirow{3}{*}{ Event Window } & \multicolumn{4}{|c|}{ Firms Issuing Mandatory Convertibles } \\
\cline { 2 - 5 } & All & $\begin{array}{c}\text { All Excluding } \\
\text { Concurrent Stock } \\
\text { Issuers }\end{array}$ & $\begin{array}{c}\text { High Z-Score } \\
\text { Excluding Concurrent } \\
\text { Stock Issuers }\end{array}$ & $\begin{array}{c}\text { Low Z-Score } \\
\text { Excluding Concurrent } \\
\text { Stock Issuers }\end{array}$ \\
\hline \hline \multirow{3}{*}[0]{} & -0.007 & -0.012 & -0.012 & -0.011 \\
& $(-2.22)^{* *}$ & $(-3.04)^{* * *}$ & $(-1.07)$ & $(-3.61)^{* * *}$ \\
{$[-1,0]$} & -0.004 & -0.009 & -0.008 & -0.010 \\
{$[-1,+1]$} & $(-1.26)$ & $(-3.18)^{* * *}$ & $(-1.00)$ & $(-2.96)^{* * *}$ \\
& -0.004 & -0.013 & -0.021 & -0.012 \\
{$[-3,0]$} & $(-1.03)$ & $(-3.15)^{* * *}$ & $(-2.38)^{* *}$ & $(-3.06)^{* * *}$ \\
& -0.001 & -0.005 & -0.011 & 0.001 \\
{$[-3,+3]$} & $(-0.35)$ & $(-1.60)$ & $(-1.68)$ & $(0.12)$ \\
& -0.004 & -0.015 & -0.028 & -0.017 \\
& $(-0.54)$ & $(-2.24)^{* *}$ & $(-2.31)^{* *}$ & $(-2.07)^{*}$ \\
\hline
\end{tabular}

PANEL B

\begin{tabular}{|c|c|c|c|c|}
\hline \multirow{3}{*}{ Event Window } & \multicolumn{4}{|c|}{ Firms Issuing Mandatory Convertibles } \\
\cline { 2 - 5 } & All & $\begin{array}{c}\text { All Excluding } \\
\text { Concurrent Stock } \\
\text { and Debt Issuers }\end{array}$ & $\begin{array}{c}\text { High Z-Score } \\
\text { Excluding Concurrent } \\
\text { Stock and Debt Issuers }\end{array}$ & $\begin{array}{c}\text { Low Z-Score } \\
\text { Excluding Concurrent } \\
\text { Stock and Debt Issuers }\end{array}$ \\
\hline \hline \multirow{3}{*}[0]{} & -0.007 & -0.012 & -0.013 & -0.011 \\
{$[-1,0]$} & $(-2.22)^{* *}$ & $(-2.87)^{* * *}$ & $(-1.15)$ & $(-3.03)^{* *}$ \\
& -0.004 & -0.010 & -0.011 & -0.012 \\
{$[-1,+1]$} & $(-1.26)$ & $(-3.38)^{* * *}$ & $(-1.50)$ & $(-2.79)^{* *}$ \\
& -0.004 & -0.011 & -0.020 & -0.012 \\
{$[-3,0]$} & $(-1.03)$ & $(-2.51)^{* *}$ & $(-2.34)^{* *}$ & $(-2.40)^{* *}$ \\
& -0.001 & -0.005 & -0.011 & 0.000 \\
{$[-3,+3]$} & $(-0.35)$ & $(-1.35)$ & $(-1.64)$ & $(-0.00)$ \\
& -0.004 & -0.011 & -0.021 & -0.020 \\
& $(-0.54)$ & $(-1.59)$ & $(-1.65)$ & $(-2.21)^{* *}$ \\
\hline
\end{tabular}




\section{Table 5}

This table reports the operating performance of firms in the years prior to and after a mandatory convertible issue. Panel A reports median ratios for the issuing firms from 2 years prior to the issue year until 2 years afterwards. Panel B reports the same ratios for the non-issuing matching firms. Matching non-issuing firms are chosen by matching each issuing firm with a firm that has not ever issued mandatory convertibles, and that has not issued any security within a one month window of the issue date using the following algorithm. The nonissuer had to be in the same two-digit industry with end-of-year -1 assets within $25 \%$ to $200 \%$ of the issuing firm, and then the non-issuer with the closest operating income before depreciation, amortization, and taxes, plus interest income was chosen. The data items used to calculate the ratios are Profit margin (net income/sales), ROA (net income/assets), OIBD/assets (operating income before depreciation + interest income)/assets, OIBD/sales (operating income before depreciation + interest income)/sales, and market-to-book ratio (market value of equity/book value of equity). Panel $\mathrm{C}$ reports the difference in the medians between the mandatory convertible issuers and the matching non-issuers. Panel D tests whether in a given year the distribution of these ratios is significantly different for issuers and non-issuers. Panel E tests whether, in a specific period relative to the pre-issue year, the change in the distribution of these ratios is significantly different between issuers and non-issuers. Z-statistics are reported from the Wilcoxon matched pairs SignedRanks test, and $* * *, * *$, and $*$ denotes significance at the 1,5 , and 10 percent levels respectively.

\begin{tabular}{|c|c|c|c|c|c|}
\hline $\begin{array}{l}\text { Fiscal Year } \\
\text { Relative to } \\
\text { Offering }\end{array}$ & Profit Margin & ROA & OIBD/Assets & OIBD/Sales & $\begin{array}{l}\text { Number of } \\
\text { Firms }\end{array}$ \\
\hline \multicolumn{6}{|c|}{ Panel A: Issuer Medians } \\
\hline-2 & $5.39 \%$ & $2.90 \%$ & $9.04 \%$ & $14.02 \%$ & 28 \\
\hline-1 & $4.79 \%$ & $2.71 \%$ & $8.37 \%$ & $15.99 \%$ & 32 \\
\hline 0 & $4.28 \%$ & $1.66 \%$ & $7.75 \%$ & $13.83 \%$ & 29 \\
\hline 1 & $6.45 \%$ & $1.79 \%$ & $9.91 \%$ & $14.30 \%$ & 25 \\
\hline 2 & $6.93 \%$ & $2.34 \%$ & $8.80 \%$ & $17.56 \%$ & 23 \\
\hline \multicolumn{6}{|c|}{ Panel B: Non-Issuer Medians } \\
\hline-2 & $5.16 \%$ & $2.43 \%$ & $8.44 \%$ & $17.65 \%$ & 28 \\
\hline-1 & $4.87 \%$ & $2.83 \%$ & $8.76 \%$ & $13.31 \%$ & 32 \\
\hline 0 & $3.50 \%$ & $1.30 \%$ & $7.35 \%$ & $10.86 \%$ & 29 \\
\hline 1 & $3.00 \%$ & $2.94 \%$ & $9.83 \%$ & $12.16 \%$ & 25 \\
\hline 2 & $4.84 \%$ & $3.76 \%$ & $10.45 \%$ & $15.47 \%$ & 23 \\
\hline \multicolumn{6}{|c|}{ Panel C: Difference in Medians Between the Issuers and Matching Non-Issuers } \\
\hline-2 & $0.23 \%$ & $0.47 \%$ & $0.60 \%$ & $-3.64 \%$ & 28 \\
\hline-1 & $-0.08 \%$ & $-0.12 \%$ & $-0.39 \%$ & $2.69 \%$ & 32 \\
\hline 0 & $0.78 \%$ & $0.36 \%$ & $0.39 \%$ & $2.97 \%$ & 29 \\
\hline 1 & $3.44 \%$ & $-1.15 \%$ & $0.08 \%$ & $2.14 \%$ & 25 \\
\hline 2 & $2.10 \%$ & $-1.43 \%$ & $-1.65 \%$ & $2.09 \%$ & 23 \\
\hline \multicolumn{6}{|c|}{$\begin{array}{c}\text { Panel D: Z-statistics Testing the Yearly Equality of Distributions Between the Issuers and Matching } \\
\text { Non-Issuers Using the Wilcoxon Matched-Pairs Signed-Ranks Test }\end{array}$} \\
\hline-2 & -0.330 & 0.649 & 0.928 & -0.837 & 28 \\
\hline-1 & -0.323 & 0.049 & -0.382 & -0.402 & 32 \\
\hline 0 & -0.171 & -0.057 & -0.377 & -1.077 & 29 \\
\hline 1 & -0.672 & -0.815 & 0.262 & -0.916 & 25 \\
\hline 2 & -0.747 & -1.495 & -0.436 & -1.134 & 23 \\
\hline \multicolumn{6}{|c|}{$\begin{array}{l}\text { Panel E: Z-statistics Testing the Equality of Distributions Between the Change in the Ratios from the } \\
\text { Pre-Issue Year to Various Years After the Issue Using the Wilcoxon Matched-Pairs Signed-Ranks Test }\end{array}$} \\
\hline Year -1 to 0 & -0.057 & -0.604 & -0.996 & -0.027 & 29 \\
\hline Year -1 to +1 & -0.986 & -1.072 & -0.262 & 0.131 & 25 \\
\hline Year -1 to +2 & -1.235 & -1.040 & -0.523 & -0.089 & 23 \\
\hline
\end{tabular}




\section{Table 6}

This table reports the long run stock performance of mandatory convertible issuers relative to the $C R S P$ value weighted index and matched non-issuers for four different event windows. In Panel A cumulative average returns are calculated for mandatory convertible issuers, and the value-weighted market index. In Panel B cumulative average returns are calculated for mandatory convertible issuers, and matching non-issuers. Matching non-issuer firms are chosen on the basis of industry, size and OIBD/AT ratio using the same algorithm described in Table 5. In each panel the cumulative average returns are calculated for four different event windows; for a period of one year prior to the announcement date, for a period of one year after the announcement date, for a period of two years after the announcement date, and for a period of three years after the announcement date. For each category of firms the cumulative average returns are calculated by compounding the daily returns of firms over the relevant trading days in each event window, and then calculating the average for that particular event window. Cumulative abnormal average returns are then calculated for each event window and $t$-statistics are calculated to test if the cumulative abnormal average returns are significantly different from zero. $* * *, * *$, and * indicate significance at the 1,5 , and 10 percent level respectively.

Panel A: Cumulative returns by event years for Mandatory Convertible Issuers and the CRSP value-weighted index

\begin{tabular}{|l|c|c|c|c|}
\hline & $\begin{array}{c}\text { Year Prior to } \\
\text { Issue }\end{array}$ & Year 1 & Year 2 & Year 3 \\
\hline \hline Mandatory Conv. Issuers & $31.94 \%$ & $18.48 \%$ & $31.69 \%$ & $39.81 \%$ \\
VW - Index & $18.06 \%$ & $12.00 \%$ & $28.18 \%$ & $44.20 \%$ \\
Average Abnormal Return & $13.88 \%$ & $6.49 \%$ & $3.50 \%$ & $-4.40 \%$ \\
$t$ - statistics & $2.90 * * *$ & 1.03 & 0.36 & -0.34 \\
Sample Size & 65 & 56 & 54 & 44 \\
\hline
\end{tabular}

Panel B: Cumulative returns by event years for Mandatory Convertible Issuers and an Industry-Size Matched

\begin{tabular}{|l|c|c|c|c|}
\hline & $\begin{array}{c}\text { Year Prior to } \\
\text { Issue }\end{array}$ & Year 1 & Year 2 & Year 3 \\
\hline \hline Mandatory Conv. Issuers & $22.14 \%$ & $21.52 \%$ & $17.68 \%$ & $1.33 \%$ \\
Matched Non-Issuers & $13.36 \%$ & $9.30 \%$ & $27.45 \%$ & $22.17 \%$ \\
Average Abnormal Return & $8.79 \%$ & $12.22 \%$ & $-9.77 \%$ & $-20.83 \%$ \\
$t$ - statistics & 0.67 & 1.09 & -0.55 & -1.11 \\
Sample Size & 28 & 23 & 22 & 18 \\
\hline
\end{tabular}




\section{Table 7}

This table reports time series regressions of monthly returns of mandatory convertible issuers using the FamaFrench (1993) three-factor model. The monthly returns are aligned in event time with month 0 representing the issue announcement month. The cross-sectional regression:

$$
\left(R_{p t}-R_{f t}\right)=\alpha_{t}+\beta_{t}\left(R_{m t}-R_{f t}\right)+s_{t} S M B_{t}+h_{t} H M L_{t}+\varepsilon_{p t}
$$

is run in each month $t$. $R_{p t}$ is the return on the portfolio of mandatory convertible issuers in month $t$; $R_{m t}$ is the return on the market index in month $t ; R_{f t}$ is the return on the risk-free asset in month $t ; S M B_{t}$ is the return on small firms minus the return on large firms in month $t$; and $H M L_{t}$ is the return on high book-to-market stocks minus the return on low book-to-market stocks in month $t$. The factor definitions are described in Fama and French (1993). The intercept of the regression $\alpha_{t}$ is an estimate of the average abnormal performance in month $t$. The number of firms in the portfolio of mandatory convertible issuers ranges from 44 to 69 , with multiple issues by the same firm being excluded from the regressions. In Panel A the three-factor model is run by using the $C R S P$ value-weighted index as the market index, whereas in Panel $\mathrm{B}$ the CRSP equally-weighted index is used as the market index. In both panels the results are presented for four different event windows from 12 months prior to the announcement date till 36 months after the announcement of the mandatory convertible issue. The $t$ statistics are presented in parenthesis and are calculated using the time series standard deviation of the average monthly abnormal returns. $* * *, * *$, and $*$ indicate significance at the 1,5 , and 10 percent level respectively.

Panel A: Average annual abnormal returns and sensitivities to Fama-French factors using the three factor model and the value weighted index

\begin{tabular}{|c|c|c|c|c|}
\hline & Months -12 to -1 & Months 0 to 12 & Months 13 to 24 & Months 25 to 36 \\
\hline \multirow[t]{2}{*}{ Alpha } & 0.007 & 0.001 & -0.005 & 0.003 \\
\hline & $(0.60)$ & $(0.05)$ & $(-0.32)$ & $(0.15)$ \\
\hline \multirow[t]{2}{*}{ Market Index } & 1.234 & 1.334 & 1.375 & 1.098 \\
\hline & $(2.63)^{* * *}$ & $(2.07)^{* *}$ & $(2.55)^{* * *}$ & $(2.14)^{* *}$ \\
\hline \multirow[t]{2}{*}{ SMB portfolio } & 0.386 & 0.177 & 0.272 & 0.170 \\
\hline & $(0.53)$ & $(0.53)$ & $(0.66)$ & $(0.21)$ \\
\hline \multirow[t]{2}{*}{ HML portfolio } & 0.477 & 0.831 & 0.961 & 0.660 \\
\hline & $(0.65)$ & $(1.45)$ & $(2.05)^{* *}$ & $(0.92)$ \\
\hline$R_{a d j}^{2}$ & 0.212 & 0.203 & 0.177 & 0.160 \\
\hline \multicolumn{5}{|c|}{$\begin{array}{l}\text { Panel B: Average annual abnormal returns and sensitivities to Fama-French factors using the three factor } \\
\text { model and the equally weighted index }\end{array}$} \\
\hline & Months -12 to -1 & Months 0 to 12 & Months 13 to 24 & Months 25 to 36 \\
\hline \multirow[t]{2}{*}{ Alpha } & 0.012 & 0.007 & -0.001 & 0.005 \\
\hline & $(1.18)$ & $(0.36)$ & $(-0.03)$ & $(0.24)$ \\
\hline \multirow[t]{2}{*}{ Market Index } & 0.790 & 0.990 & 0.964 & 0.620 \\
\hline & $(1.41)$ & $(1.51)$ & $(1.65)$ & $(0.91)^{*}$ \\
\hline \multirow[t]{2}{*}{ SMB portfolio } & -0.275 & -0.276 & -0.365 & -0.191 \\
\hline & $(-0.38)$ & $(-0.52)$ & $(-0.63)$ & $(-0.23)$ \\
\hline \multirow[t]{2}{*}{ HML portfolio } & 0.006 & 0.510 & 0.515 & 0.281 \\
\hline & $(0.01)$ & $(1.03)$ & $(1.13)$ & $(0.41)$ \\
\hline$R_{a d j}^{2}$ & 0.165 & 0.160 & 0.130 & 0.133 \\
\hline
\end{tabular}

